\title{
Ketogenesis prevents diet-induced fatty liver injury and hyperglycemia
}

\author{
David G. Cotter, ${ }^{1,2}$ Baris Ercal, ${ }^{1}$ Xiaojing Huang, ${ }^{1,3}$ Jamison M. Leid, ${ }^{1}$ D. André d'Avignon, ${ }^{3}$ Mark J. Graham, ${ }^{4}$ Dennis J. Dietzen, ${ }^{2}$ \\ Elizabeth M. Brunt, ${ }^{5}$ Gary J. Patti, ${ }^{3,6}$ and Peter A. Crawford ${ }^{1,6,7}$ \\ 'Department of Medicine, Center for Cardiovascular Research, ${ }^{2}$ Department of Pediatrics, and ${ }^{3}$ Department of Chemistry, Washington University, St. Louis, Missouri, USA. ${ }^{4}$ Isis Pharmaceuticals Inc., Carlsbad, \\ California, USA. ${ }^{5}$ Department of Pathology and Immunology and ${ }^{6}$ Department of Genetics, Washington University, St. Louis, Missouri, USA. ${ }^{7}$ Sanford-Burnham Medical Research Institute, Orlando, Florida, USA.
}

\begin{abstract}
Nonalcoholic fatty liver disease (NAFLD) spectrum disorders affect approximately 1 billion individuals worldwide. However, the drivers of progressive steatohepatitis remain incompletely defined. Ketogenesis can dispose of much of the fat that enters the liver, and dysfunction in this pathway could promote the development of NAFLD. Here, we evaluated mice lacking mitochondrial 3-hydroxymethylglutaryl CoA synthase (HMCCS2) to determine the role of ketogenesis in preventing diet-induced steatohepatitis. Antisense oligonucleotide-induced loss of HMCCS2 in chow-fed adult mice caused mild hyperglycemia, increased hepatic gluconeogenesis from pyruvate, and augmented production of hundreds of hepatic metabolites, a suite of which indicated activation of the de novo lipogenesis pathway. High-fat diet feeding of mice with insufficient ketogenesis resulted in extensive hepatocyte injury and inflammation, decreased glycemia, deranged hepatic TCA cycle intermediate concentrations, and impaired hepatic gluconeogenesis due to sequestration of free coenzyme A (CoASH). Supplementation of the CoASH precursors pantothenic acid and cysteine normalized TCA intermediates and gluconeogenesis in the livers of ketogenesis-insufficient animals. Together, these findings indicate that ketogenesis is a critical regulator of hepatic acyl-CoA metabolism, glucose metabolism, and TCA cycle function in the absorptive state and suggest that ketogenesis may modulate fatty liver disease.
\end{abstract}

\section{Introduction}

Nonalcoholic fatty liver disease (NAFLD) and nonalcoholic steatohepatitis (NASH) are now the most common causes of liver disease in Western countries (1). NAFLD-induced liver failure is one of the most common reasons for liver transplantation. NAFLD increases the risk of developing type 2 diabetes, worsens glycemic control, and contributes to the pathogenesis of cardiovascular disease and chronic kidney disease (2-4). The pathogenic mechanisms of NAFLD and NASH are incompletely understood but are thought to involve abnormalities of hepatocyte metabolism, hepatocyte autophagy and endoplasmic reticulum stress, hepatic immune cell function, adipose tissue inflammation, and systemic inflammatory mediators $(2,4-6)$. Perturbations of carbohydrate, lipid, and amino acid metabolism occur in and contribute to obesity, diabetes, and NAFLD in humans and in model organisms (reviewed in refs. 7-11). While hepatocyte abnormalities in cytoplasmic lipid metabolism are commonly observed in NAFLD (12), the role of mitochondrial metabolism, which governs the oxidative and terminal "disposal" of fats, in NAFLD pathogenesis is less clear. Nonetheless, most investigators agree that abnormalities of mitochondrial metabolism occur in and contribute to NAFLD (reviewed in refs. 13-15).

Authorship note: David C. Cotter and Baris Ercal contributed equally to this work. Conflict of interest: Mark J. Graham is an employee and shareholder of Isis Pharmaceuticals Inc.

Submitted: March 31, 2014; Accepted: September 18, 2014

Reference information: J Clin Invest. 2014;124(12):5175-5190. doi:10.1172/JCI76388.
Ketogenesis can dispose of as much as two-thirds of the fat entering the liver (16). Thus, dysregulation of ketone body metabolism could potentially contribute to NAFLD pathogenesis. Hepatic ketogenesis is activated in states of high fatty acid and diminished carbohydrate availability and/or when circulating insulin concentrations are very low (17-20). Within hepatic mitochondria, ketogenic reactions condense $\beta$-oxidation-derived acetyl-CoA into the ketone bodies acetoacetate (AcAc) and $\beta$ hydroxybutyrate $(\beta \mathrm{OHB})$. In doing so, ketogenesis disposes of acetyl-CoA generated in excess of the liver's own energy needs and simultaneously recycles 2 moles of free coenzyme A (CoASH) per mole of ketone produced (reviewed in refs. 17, 19, 20). Robust ketogenesis is limited to hepatocytes due to relatively restricted expression of the fate-committing ketogenic enzyme mitochondrial 3-hydroxymethylglutarylCoA synthase (HMGCS2) under normal conditions (21). In contrast, oxidative disposal of ketone bodies is nearly ubiquitous, as all cells except hepatocytes express the fate-committing enzyme of ketone body oxidation succinyl-CoA:3-oxoacid CoA transferase (SCOT) $(22,23)$. Within the mitochondria of extrahepatic tissues, $\beta \mathrm{OHB}$ is oxidized to AcAc, which is then directed toward the TCA cycle for terminal oxidation via a reaction uniquely catalyzed by SCOT (17). Despite its high capacity as a disposal pathway for hepatic fatty acids, ketone body metabolism has been overlooked as a potential therapeutic target in NAFLD.

Through incompletely defined mechanisms, obesity-associated hyperinsulinemia suppresses ketogenesis, creating a state of relative ketogenic insufficiency and leading to hypoketonemia in obese animal models and humans when compared with lean 
A

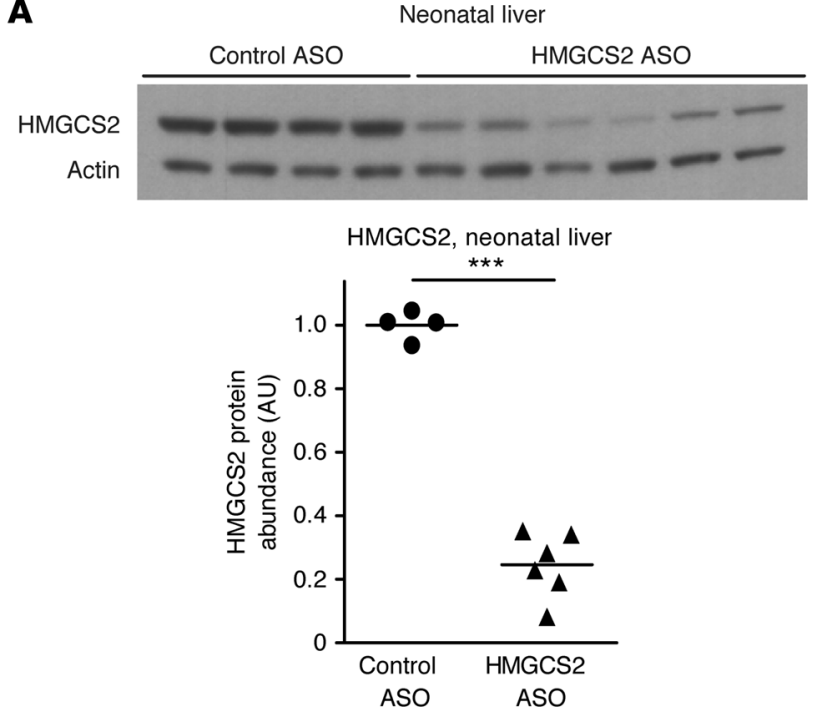

D

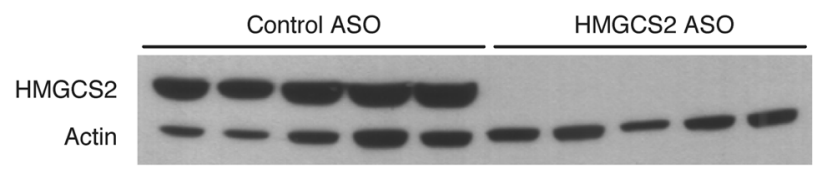

B
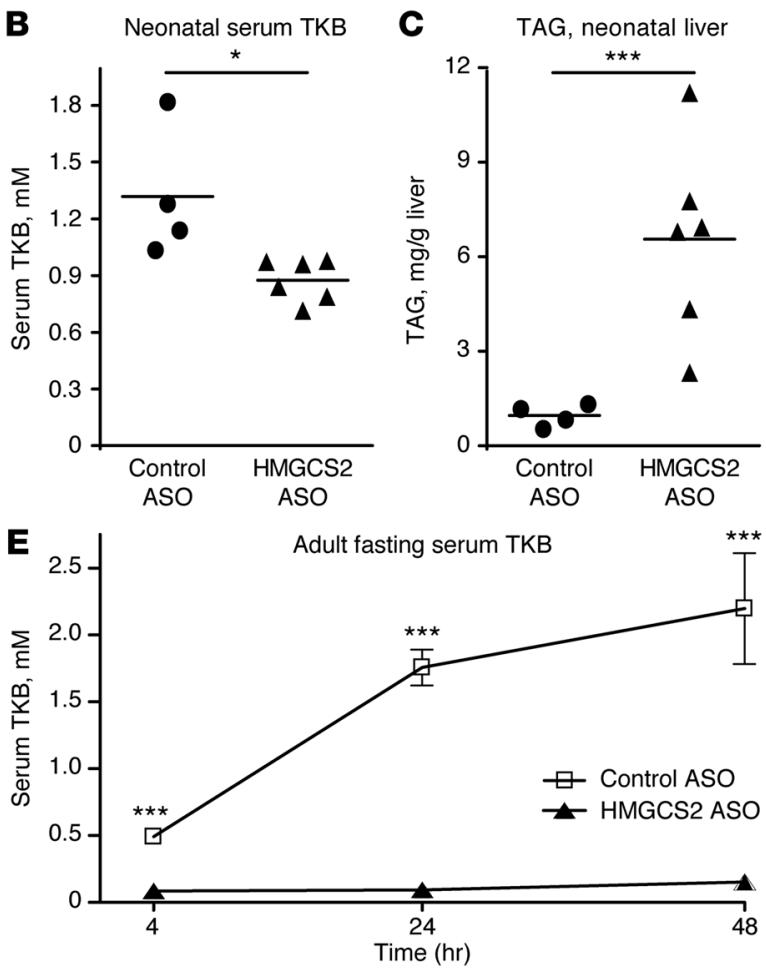

Figure 1. Ketogenic insufficiency in mice treated with HMGCS2 ASO. (A) Immunoblot for HMCCS2 and actin using protein lysates derived from livers of neonatal mice treated with either a scrambled sequence control ASO or HMCCS2 ASO. Mice were treated with ASO daily for 11 days, beginning on the second day of life, and tissues and serum were collected on P12. Normalized protein abundance is quantified below. (B) Serum total ketone body (TKB)

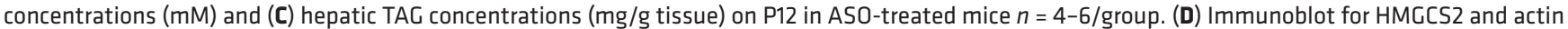
using protein lysates derived from the livers of adult mice treated with control or HMCCS2 ASO biweekly for 4 weeks beginning at 6 weeks of age. (E) Serum TKB concentrations (mM) during fasting in adult mice treated with ASOs for 4 weeks. $n=3-5 /$ group. ${ }^{*} P<0.05$, ${ }^{* *} P<0.001$ by Student's $t$ test versus HMCCS2 ASO-treated mice, or as indicated.

controls (24-29). To test the hypothesis that impaired ketogenesis, even in carbohydrate-replete and thus "nonketogenic" states, contributes to abnormal glucose metabolism and provokes steatohepatitis, we generated a mouse model of marked ketogenic insufficiency and used complementary systems physiological approaches and ${ }^{13} \mathrm{C}$-labeling-based high-resolution measures of metabolic dynamics to characterize the wide-ranging effects of ketogenic impairment.

\section{Results}

Ketogenic insufficiency causes abnormal hepatic glucose and lipid metabolism. The ability of ketogenesis to influence hepatic glucose and lipid homeostasis has only been preliminarily characterized. To determine the consequences of impaired ketogenesis during the highly ketogenic neonatal period, suckling mice were injected s.c. $(25 \mathrm{mg} / \mathrm{kg}$ ) with an Hmgcs2-targeted antisense oligonucleotide (ASO) daily, beginning on the second day of extrauterine life. Compared with littermates injected with scrambled sequence control ASO, we found that HMGCS2 ASO treatment decreased hepatic HMGCS2 protein abundance by $70 \%$ by postnatal day 12 (P12) (Figure 1A). These mice exhibited normal body weights and blood glucose concentrations and displayed mildly decreased plasma ketone body concentrations $(0.9 \pm 0.05 \mathrm{mM}$ vs. $1.3 \pm 0.17$ $\mathrm{mM}$ in controls, $n=4-6 /$ group, $P<0.05$; Figure $1 \mathrm{~B}$ and Supplemental Figure 1, A and B; supplemental material available online with this article; doi:10.1172/JCI76388DS1). Intriguingly, this partial loss of ketogenesis was associated with a nearly 7-fold increase in hepatic triacylglycerol (TAG) concentrations $(6.6 \pm 1.2 \mathrm{mg} / \mathrm{g}$ vs. $0.96 \pm 0.2 \mathrm{mg} / \mathrm{g}$ tissue in controls, $n=4-6 /$ group, $P<0.001$; Figure 1C). To determine whether HMGCS2-mediated ketogenesis plays a role in a model of adult NAFLD, we administered i.p. injections of HMGCS2 ASO ( $25 \mathrm{mg} / \mathrm{kg}$ biweekly for 4 weeks) into C57BL/6 male mice maintained on a standard low-fat chow diet. After 4 weeks, we found that hepatic $H m g c s 2$ transcript abundance was decreased by $88 \%$ compared with that in mice treated with control ASO ( $n=8-10$ per group, $P<0.001$ ), without diminishing the scant Hmgcs 2 transcript abundance normally observed in s.c. adipose tissue (ref. 30 and Supplemental Figure 1, C and D). Immunoreactive HMGCS2 was eliminated from the liver in HMGCS2 ASO-treated mice (Figure 1D). ASO treatment did not diminish the protein abundance of cytoplasmic 3-hydroxymethylglutaryl-CoA synthase (HMGCS1), which catalyzes the penultimate reaction in mevalonate synthesis (Supplemental Figure 1E).

HMGCS2 ASO-treated mice exhibited markedly blunted ketonemia in both baseline (fed) and nutrient-deprived states (Figure $1 \mathrm{E})$. To confirm the inability of HMGCS2 ASO-treated mice to effectively incorporate fatty acid-derived carbon into ketone bodies, livers from control and HMGCS2 ASO-treated mice were perfused ex vivo via the portal vein with an oxygenated buffer containing the fatty acid $\left[{ }^{13} \mathrm{C}\right]$ octanoic acid. Quantitative mapping 
A
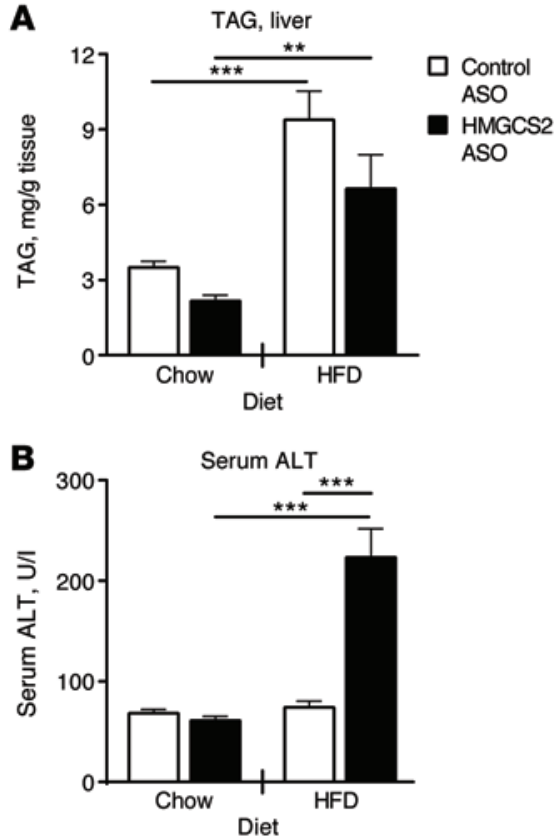

C

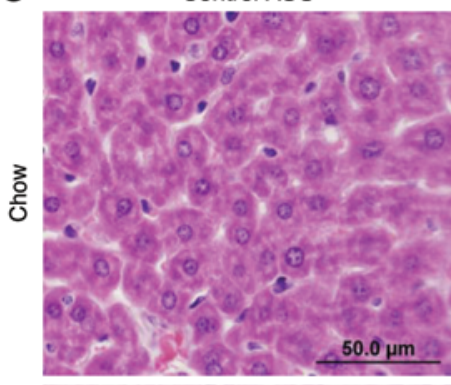

Control ASO
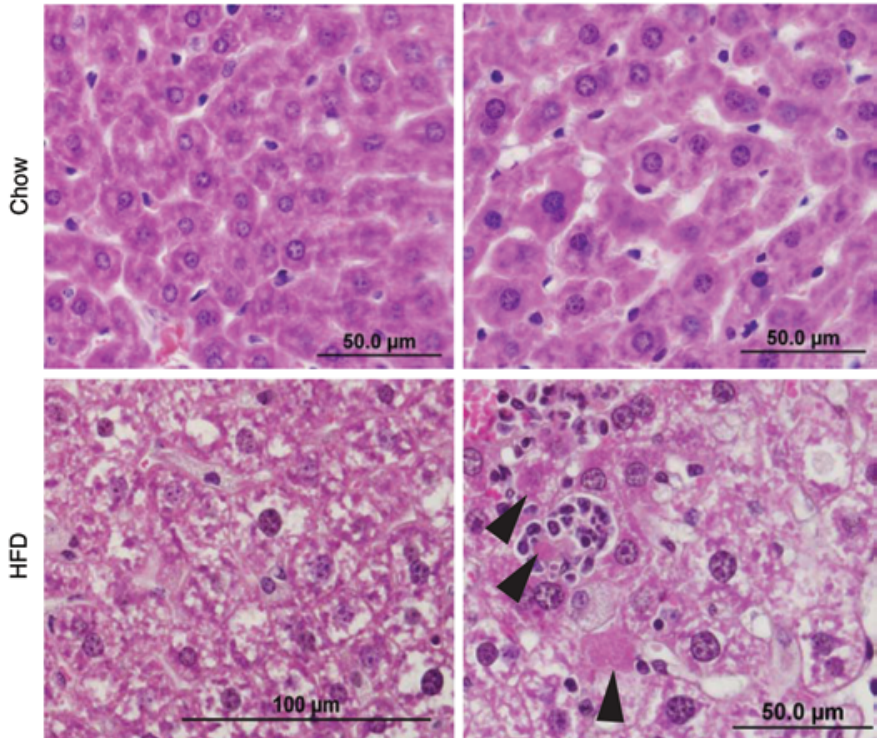

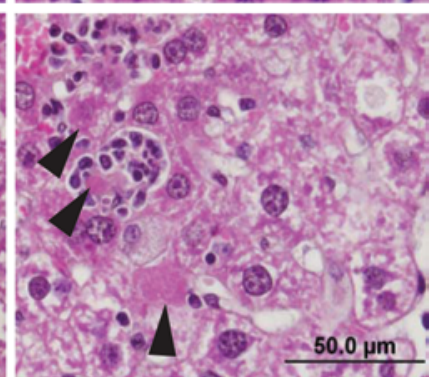

D
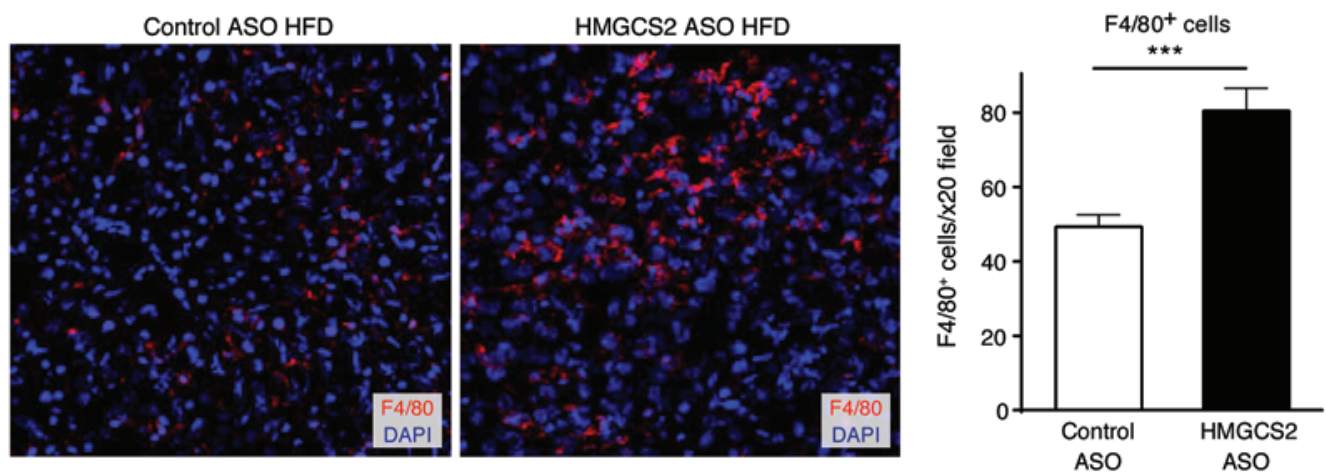

E
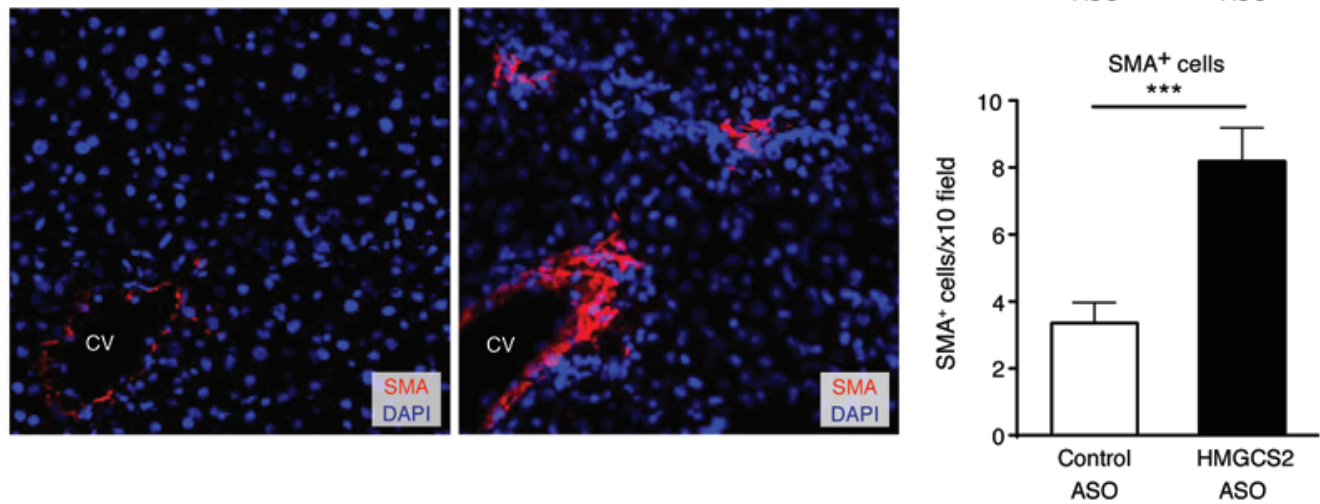

Figure 2. Hepatic injury in HFD-fed ketogenesis-insufficient mice. (A) Hepatic TAG concentrations (mg/g tissue) and (B) serum ALT activity (U/I) in ASO-treated mice fed a standard low-fat chow diet (Chow) for 4 weeks or an HFD for 8 weeks; $n=4$-5/group. (C) Representative H\&E-stained sections of liver from ASO-treated mice fed the indicated diet. Arrowheads indicate dying hepatocytes (acidophil bodies). Scale bars: $50 \mu \mathrm{m}$ and $100 \mu \mathrm{m}$ (bottom left panel). (D) Representative $\times 20$ fields showing immunostaining for $\mathrm{F} 4 / 80^{+}$and (E) SMA ${ }^{+}$cells in cryosections of liver from ASO-treated mice fed an HFD for 8 weeks. Quantification for each is shown on the right. $n=5$ random $\times 20$ fields/liver and 19 random $\times 10$ fields/liver, respectively ( $n=3$ animals/group). ${ }^{* *} P<0.01,{ }^{* *} P<0.001$ by Student's $t$ test or 2-way ANOVA.

of the ${ }^{13} \mathrm{C}$-label using ${ }^{13} \mathrm{C}$-edited proton NMR profiling (31-34) revealed markedly blunted incorporation of the label into $\beta \mathrm{OHB}$ in HMGCS2 ASO-treated mice in both the fed and overnight-fasted states. These results confirm that HMGCS2 is required for effective derivation of ketone bodies from fatty acids and indicate that livers of these mice exhibit impaired ketogenesis, i.e., are ketogenesis insufficient (Supplemental Figure 1F). Despite exhibiting marked ketogenic impairment, we observed that HMGCS2 ASOtreated mice fed a standard low-fat chow diet did not differ in body weight, body composition, or food intake compared with control 

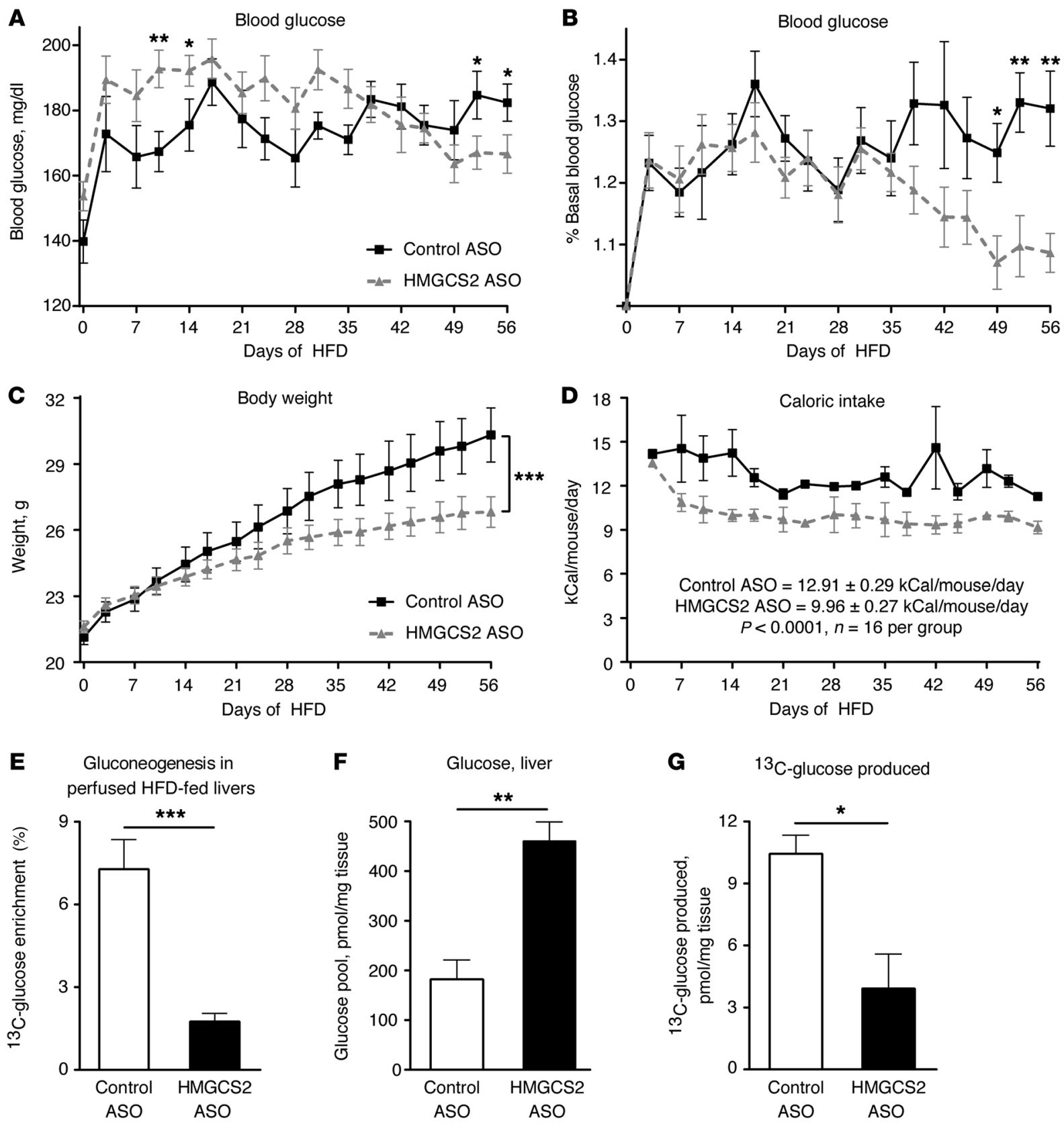

Figure 3. Diminished glycemia and hepatic gluconeogenesis in HFD-fed ketogenesis-insufficient mice. (A) Blood glucose (mg/dl) and (B) percentage of basal blood glucose in ASO-treated mice beginning at the onset of 60\% HFD feeding. $n=8-10 /$ group. (C) Body weight and (D) caloric intake (kcal/mouse/ day) during $60 \% \mathrm{HFD}$ maintenance and ASO treatment. $n=8-10 /$ group. ${ }^{* * *} P<0.001$ by linear regression $t$ test. (E) Quantification of fractional ${ }^{13} \mathrm{C}$ enrichment of glucose from $\left[{ }^{13} \mathrm{C}\right.$ ]pyruvate (a surrogate for gluconeogenesis) determined by ${ }^{13}$ C-edited proton NMR spectroscopy in liver extracts of $60 \% \mathrm{HFD}$-fed ASO-treated mice perfused via the portal vein with $\left[{ }^{13} \mathrm{C}\right]$ lactate and $\left[{ }^{13} \mathrm{C}\right]$ pyruvate in a physiological ratio. $n=4-5 /$ group. (F) Total hepatic glucose concentration (pmol/mg tissue) and (C) moles of ${ }^{13} \mathrm{C}$-glucose produced from $\left[{ }^{13} \mathrm{C}\right]$ lactate and $\left[{ }^{13} \mathrm{C}\right]$ pyruvate, quantified by NMR profiling of perfused liver extracts from ASO-treated mice fed a 60\% HFD for 8 weeks. $n=4-5 /$ group. ${ }^{*} P<0.05,{ }^{* *} P<0.01,{ }^{* * *} P<0.001$ by Student's $t$ test.

mice (Supplemental Figure 2, A-C). HMGCS2 ASO-treated mice also exhibited normal serum free fatty acid (FFA) and TAG concentrations and a normal physiologic distribution of residual $\beta \mathrm{OHB}$ and AcAc (Supplemental Figure 2, D-F). Interestingly, HMGCS2 ASO-treated mice displayed mild, but very consistently elevated, blood glucose concentrations $(160.9 \pm 3.2 \mathrm{mg} / \mathrm{dl}$ vs. $145.0 \pm 3.4$ $\mathrm{mg} / \mathrm{dl}$ in controls, $n=28-36 /$ group, $P=0.0013$ ), without changes in serum insulin concentrations (Supplemental Figure 2, G and H).
Ketogenic insufficiency causes hepatic inflammation, injury, and altered glucose metabolism in the setting of carbohydrate-replete overnutrition. To determine the effects of ketogenic insufficiency in the context of overnutrition, mice previously receiving ASOs for 2 weeks while on a standard low-fat chow diet were then maintained for 8 weeks on a $60 \%$ high-fat diet (HFD) commonly used to induce hyperglycemia, hepatic steatosis, and inflammation in WT mice. HMGCS2 immunoblots indicated that hepatic HMGCS2 

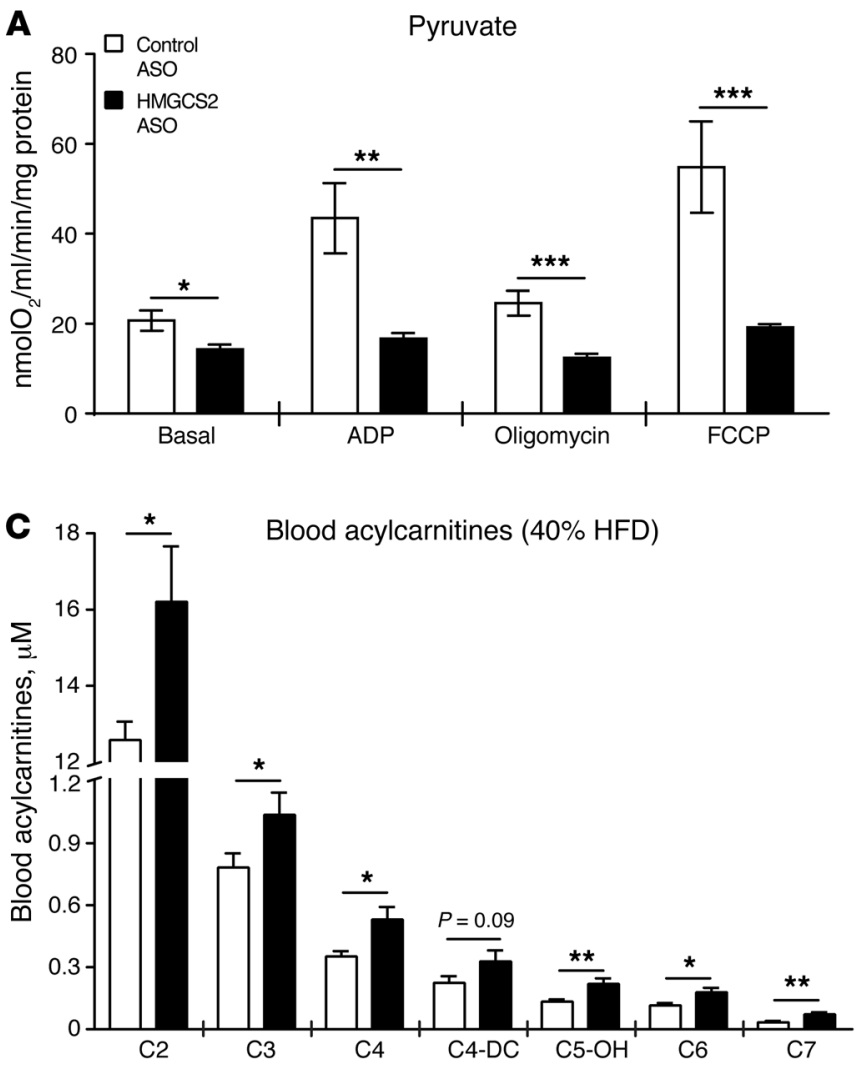

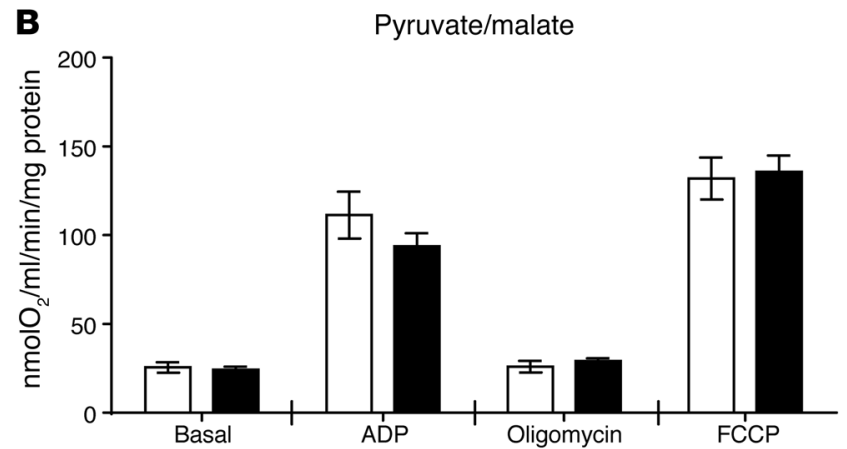

D Blood acylcarnitines (60\% HFD)

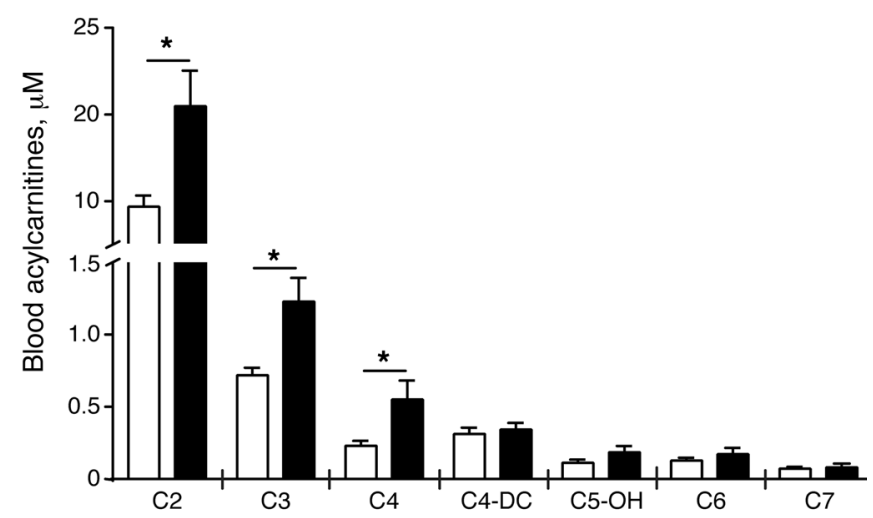

Figure 4. Mitochondrial acetyl-CoA and short- and medium-chain acylcarnitine accumulation in ketogenesis-insufficient mice. Mitochondrial respiration determined by the oxygen consumption rate of isolated mitochondria. State 2 (basal), state 3 (ADP), state 4 (oligomycin), and uncoupled (FCCP) respiration of mitochondria isolated from the livers of standard chow diet-fed ASO-treated mice using either (A) $10 \mathrm{mM}$ pyruvate alone or (B) $10 \mathrm{mM}$ pyruvate with $5 \mathrm{mM}$ malate as an anaplerotic substrate. $n=6$-9/group. Blood acylcarnitines ( $\mu \mathrm{M}$ ) in (C) $40 \%$ and (D) $60 \%$ HFD-fed ASO-treated mice, determined by MS/MS. $n=4-10 /$ group. ${ }^{*} P<0.05,{ }^{* *} P<0.01,{ }^{* * *} P<0.001$, by Student's $t$ test.

protein abundance was decreased by $93 \%$ within 2 weeks of ASO treatment (Supplemental Figure 3A) and continued to decrease to undetectable levels by the end of the 8-week HFD-feeding interval, during which time ASO treatments were continued on a biweekly basis (Supplemental Figure 3B). While serum TAG and FFA concentrations did not differ between groups of HFD-fed mice (Supplemental Figure 3, C and D), serum ketone body concentrations were significantly decreased in HFD-fed HMGCS2 ASO-treated mice $(0.04 \pm 0.02 \mathrm{mM}$ vs. $0.26 \pm 0.03 \mathrm{mM}, P<0.0001, n=8-10 /$ group; Supplemental Figure 3E). After 8 weeks of HFD feeding, we found that control and HMGCS2 ASO-treated mice exhibited mildly increased hepatic TAG concentrations (Figure 2A). As expected, serum alanine aminotransferase (ALT) activity, a circulating biomarker of hepatocellular injury, was not elevated in HFD-fed control mice, given the relatively brief duration of the HFD (Figure 2B). Conversely, HFD feeding increased serum ALT activity by nearly 4-fold in HMGCS2 ASO-treated mice compared with mice maintained on a standard chow diet $(223.5 \pm 37.7$ $\mathrm{U} / 1$ vs. $61.2 \pm 4.0 \mathrm{U} / \mathrm{l}$ in chow-fed HMGCS2 ASO-treated mice, $n=4-5$ /group, $P<0.0001$ ) and by 3 -fold compared with the HFDfed control mice $(223.5 \pm 37.7 \mathrm{U} / 1$ vs. $74.3 \pm 6.1 \mathrm{U} / \mathrm{l}$ in control mice, $n=4$ /group, $P<0.0001$; Figure $2 \mathrm{~B})$. Blinded histopathologic evaluation of liver tissue from ketogenesis-insufficient mice fed an HFD revealed evidence of injury, including panacinar inflam- matory infiltrates and acidophil bodies (dying hepatocytes). We did not observe these findings in livers from HFD-fed control ASO-treated mice or chow-fed HMGCS2-deficient mice (Figure 2C). Livers of HFD-fed HMGCS2 ASO-treated mice also exhibited increased numbers of sinusoidal macrophages, as confirmed by F $4 / 80$ immunohistochemical staining $(80.5 \pm 6.1$ vs. $49.3 \pm 3.2$ $\mathrm{F} 4 / 80^{+}$cells $/ \times 20$ field, $P<0.001, n=5$ fields/liver from 3 livers/ group; Figure 2D), and increased evidence of stellate cell activation, as indicated by anti-smooth muscle actin (SMA) immunostaining ( $8.2 \pm 1.0$ vs. $3.4 \pm 0.6 \mathrm{SMA}^{+}$cells $/ \times 10$ field, $P<0.001$, $n=19$ fields/liver from 3 livers/group; Figure 2E). These results indicate that ketogenic insufficiency in the setting of overnutrition accelerates a pronounced NASH-like phenotype.

To determine the metabolic effects of ketogenic insufficiency in the setting of overnutrition, we monitored blood glucose concentrations during the course of HFD administration. While blood glucose levels were higher in HMGCS2 ASO-treated mice at the onset of HFD feeding, glycemia began to decline in these mice after 5 weeks of maintenance on this diet (Figure 3, A and B). HFD-fed HMGCS2 ASO-treated mice also gained significantly less weight than did control mice (final weight after HFD feeding: $26.8 \pm 0.7 \mathrm{~g}$ vs. $30.3 \pm 1.2 \mathrm{~g}$ in controls, $P=0.019$, $n=8-10 /$ group $)$ and ingested fewer calories $(9.96 \pm 0.3 \mathrm{kcal} /$ mouse/day vs. $12.9 \pm 0.3 \mathrm{kcal} / \mathrm{mouse} /$ day in controls, $P<0.0001$, 
A
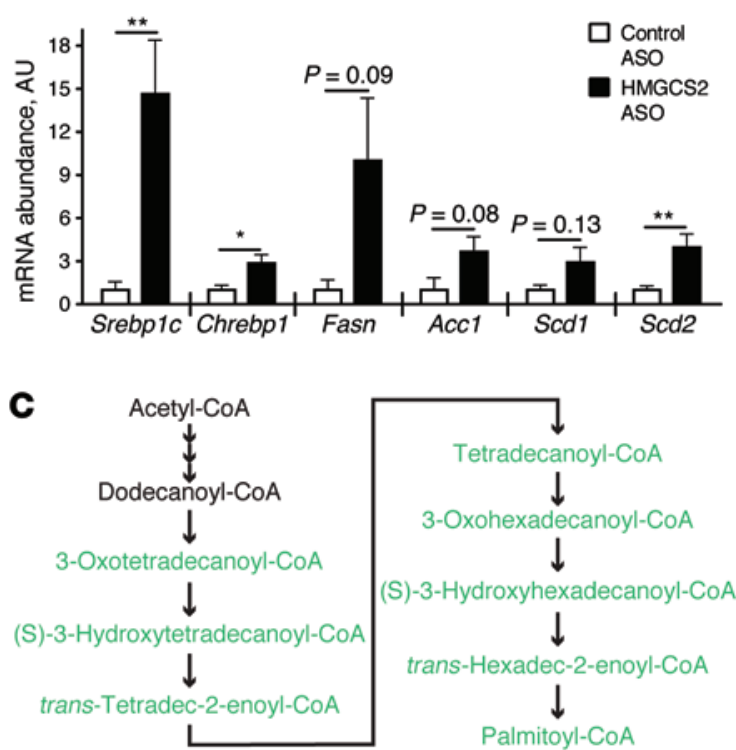

D

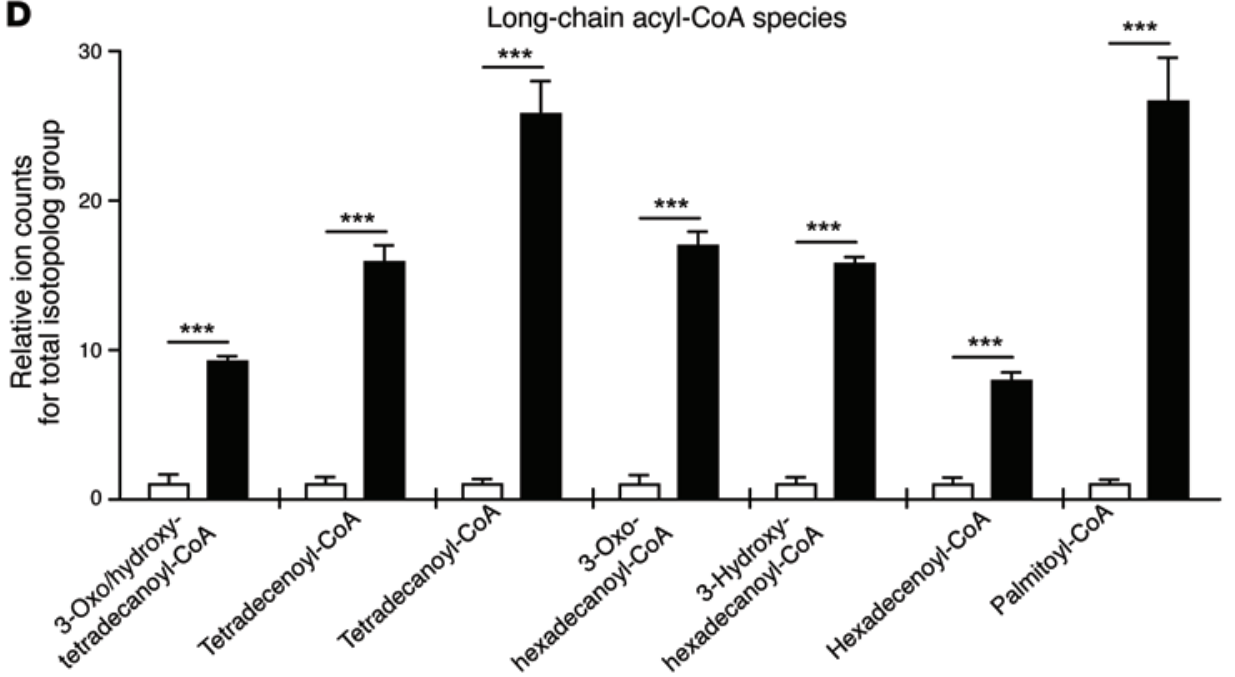

B

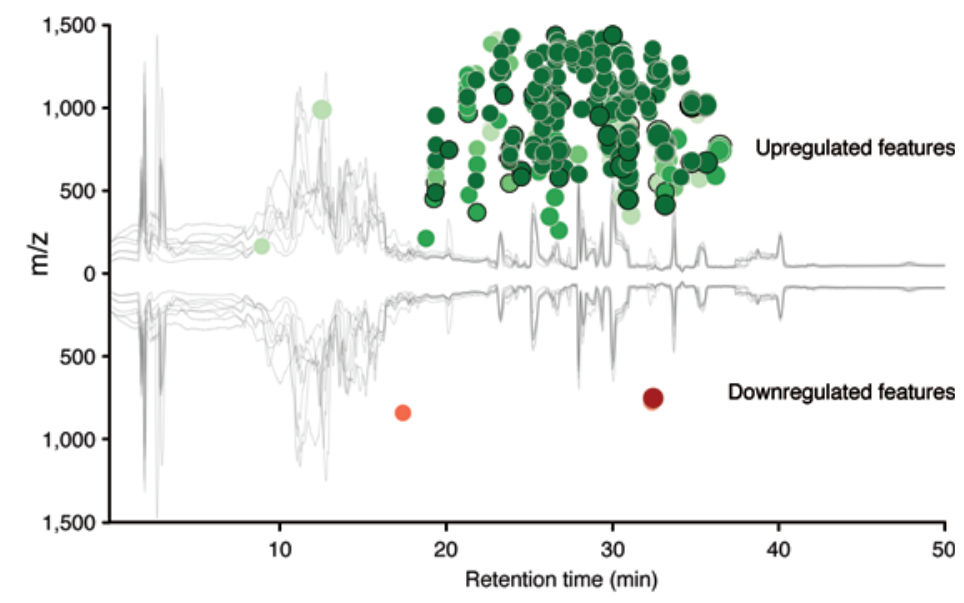

$\mathbf{E}$
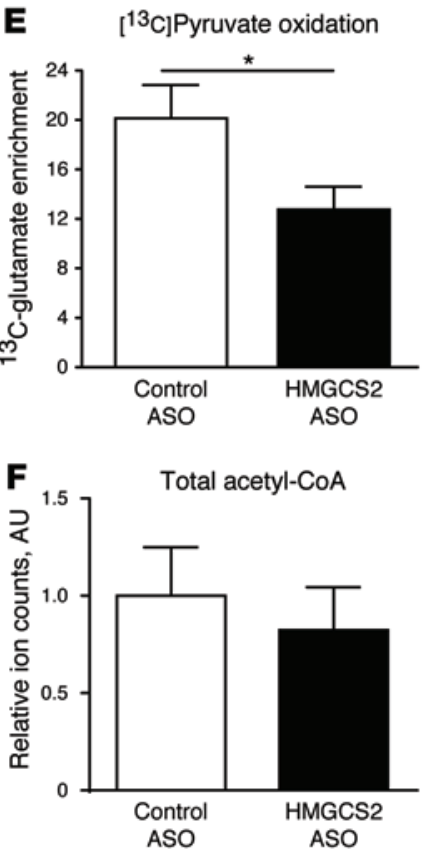

Figure 5. Altered DNL signatures in ketogenesis-insufficient mice. (A) Transcript abundances of DNL mediators in livers from ASO-treated mice. $n=5$-10/ group. Srebp1c, sterol regulatory element-binding protein 1c; Chrebp1, carbohydrate-responsive element-binding protein 1; Fasn, fatty acid synthase; Acc1, acetyl-CoA carboxylase; Scd1 and Scd2, stearoyl-CoA desaturase 1 and 2. (B) XCMS Online cloud plot of 495 dysregulated features in HMGCS2 ASO-treated livers perfused with $\left[{ }^{13} \mathrm{C}\right]$ pyruvate and $\left[{ }^{13} \mathrm{C}\right]$ lactate compared with those of control livers. The radius (upregulated and downregulated features relative to controls are green and red, respectively) and shading darkness of each circle are proportional to each circle's fold-change and $P$ value, respectively. $n=4 /$ group. (C) Schematic adapted from the KEGG (refs. 38, 39), depicting the 14- and 16-carbon-long intermediates produced during fatty acid synthesis. Species putatively identified as features that are significantly enriched in HMGCS2 ASO-perfused livers are highlighted in green. (D) Untargeted LC/MS metabolomics identification and quantification of total abundance of long-chain acyl-CoA species in the livers of ASO-treated mice perfused with $\left[{ }^{13} \mathrm{C}\right]$ pyruvate and $\left[{ }^{13} \mathrm{C}\right]$ lactate. $n=4$ /group. (E) Quantification of fractional ${ }^{13} \mathrm{C}$ enrichment of glutamate from $\left[{ }^{13} \mathrm{C}\right]$ pyruvate determined by NMR in extracts of perfused livers of ASO-treated mice. $n=7-8 /$ group. (F) Relative acetyl-CoA ion counts in the livers of ASO-treated mice perfused with lactate and pyruvate as measured by LC/MS. $n=4$ /group. ${ }^{*} P<0.05,{ }^{* *} P<0.01,{ }^{* *} P<0.001$ by Student's $t$ test or 2 -way ANOVA, as appropriate, versus HMGCS2 ASO-treated mice, or as indicated.

$n=8-10 \mathrm{mice} /$ group over 16 measurements of food intake; Figure 3, C and D). However, decreased glycemia in ketogenesis-insufficient mice was not entirely attributable to decreased caloric intake, because the capacity to support de novo glucose production from $\left[{ }^{13} \mathrm{C}\right]$ pyruvate was decreased 4 -fold in perfused livers of HFD-fed HMGCS2 ASO-treated mice $(1.8 \pm 0.3 \%$ vs. $7.3 \pm 1.1 \%$ fractional enrichment as $\left[{ }^{13} \mathrm{C}\right]$ glucose in controls, $P=0.0009, n=4-5 /$ group; Figure $3 \mathrm{E})$. While the total hepatic glucose pool was expanded in perfused livers of HFD-fed HMGCS2 ASO-treated mice (Figure 3F), de novo ${ }^{13} \mathrm{C}$-labeling of glucose from $\left[{ }^{13} \mathrm{C}\right]$ pyruvate was markedly diminished in HFD-fed HMGCS2 ASO-treated livers $(3.9 \pm 1.7$ pmol vs. 10.4 $\pm 0.9 \mathrm{pmol}\left[{ }^{13} \mathrm{C}\right]$ glucose produced $/ \mathrm{mg}$ of tissue in controls, $P=0.016, n=4-5 /$ group; Figure $3 \mathrm{G})$. Similarly to the responses to the $60 \%$ HFD, HMGCS2 ASO-treated mice maintained on a distinct $40 \%$ fat/sucrose-enriched diet for 8 weeks also exhib- 
A Gluconeogenesis in perfused

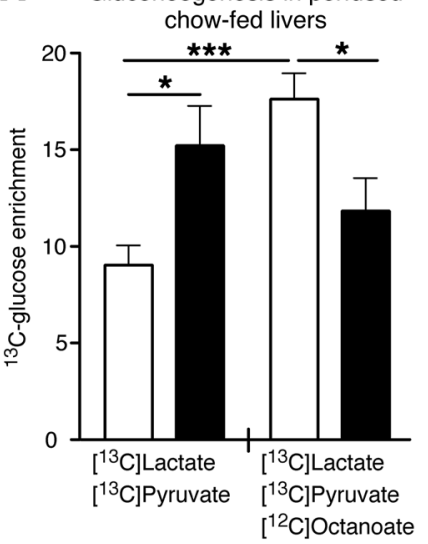

D

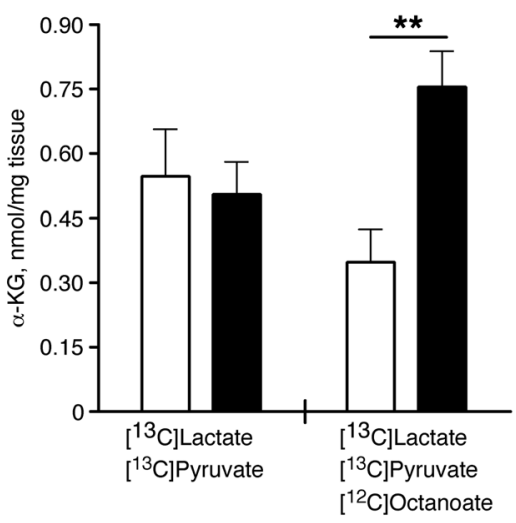

G

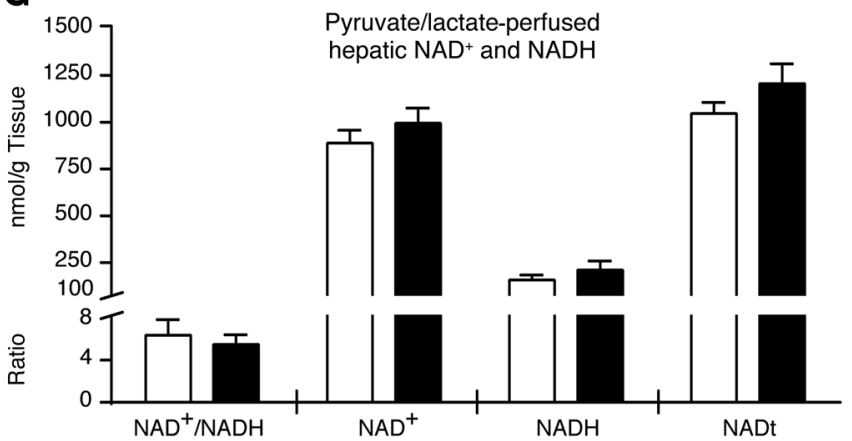

Glucose, liver

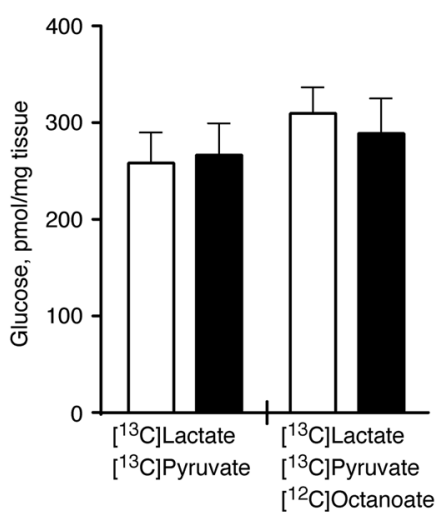

E

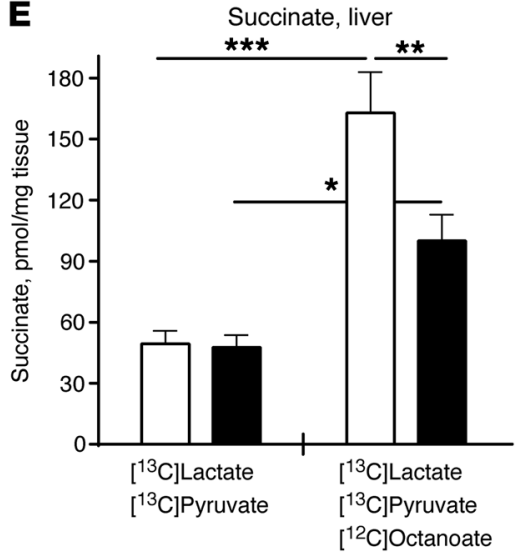

H
C

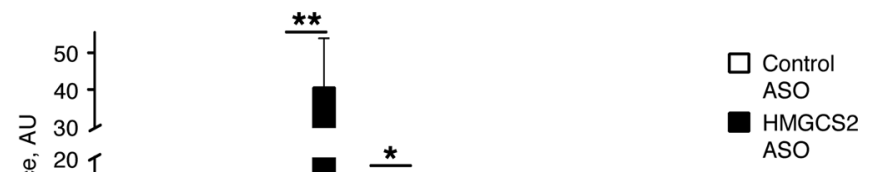

Figure 6. Hepatic metabolic reprogramming in ketogenesis-insufficient mice. (A) Quantification of ${ }^{13} \mathrm{C}$ enrichment of glucose from $\left.{ }^{13} \mathrm{C}\right]$ pyruvate and total glucose concentrations (pmol/mg tissue) (B) determined by NMR in liver extracts of standard chow diet-fed ASO-treated mice perfused with the indicated substrates. $n=7-8 /$ group. (C) Relative transcript abundances of key mediators of fatty acid oxidation and gluconeogenesis in livers from standard chow diet-fed ASO-treated mice. $n=8-10$ /group. Ppara, peroxisome proliferator-activated receptor $\alpha$; Ppargc1a, peroxisome proliferator-activated receptor $\gamma$ coactivator 1- $\alpha$; Acox1, acyl-CoA oxidase; Cpt1a, carnitine palmitoyl transferase 1- $\alpha$; Acadm, medium-chain acyl-CoA dehydrogenase; Fgf21, fibroblast growth factor 21; Me2, malic enzyme 2; Pck1, phosphoenol pyruvate carboxykinase; C6pc, glucose-6-phosphatase. (D) Quantification of total $\alpha-K C$ (nmol/mg tissue), (E) succinate (pmol/mg tissue), and (F) total glutamate concentrations ( $\mathrm{nmol} / \mathrm{mg}$ tissue) determined by NMR in liver extracts of standard chow diet-fed ASO-treated mice perfused with the indicated substrates. $n=7-8 /$ group. (C) Concentrations of oxidized, reduced, and total nicotinamide adenine dinucleotide (NAD+, NADH, and NADt, respectively; nmol/g tissue) as well as the ratio of NAD+/NADH levels in the livers of standard chow diet-fed ASO-treated mice perfused with lactate and pyruvate or $(\mathbf{H})$ with lactate and pyruvate in the presence of octanoic acid. $n=4-6 /$ group. ${ }^{*} P<0.05,{ }^{* *} P<0.01,{ }^{* *} P<0.001$ by Student's $t$ test or 2-way ANOVA, as appropriate, versus HMGCS2 ASO-treated mice, or as indicated.

ited decreased weight gain, caloric intake, body fat percentages, and blood glucose concentrations (Supplemental Figure 4, A-D). Ketogenesis-insufficient mice fed a 40\% HFD also exhibited hepatic steatosis equivalent to that of control HFD-fed mice, modestly increased serum ALT activity, and microgranuloma formation and inflammatory infiltrates in the liver (Supplemental Fig- ure $5, A-C)$. Importantly, we found that both the elevation of serum ALT activity and the degree of histopathologic evidence of hepatic inflammation were diminished in HMGCS2 ASO-treated mice fed a $40 \%$ HFD compared with those fed a $60 \%$ HFD, suggesting that chronic exposure to excess dietary fat drives the NASH-like phenotype observed in ketogenesis-insufficient mice. 
A

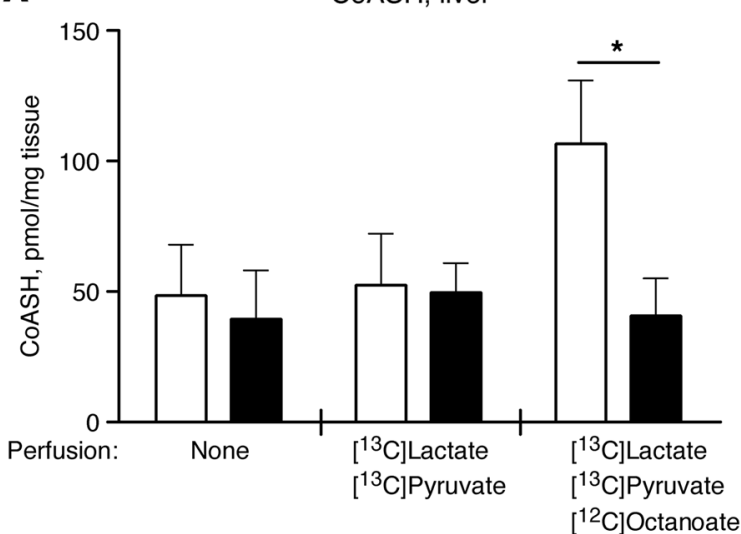

B

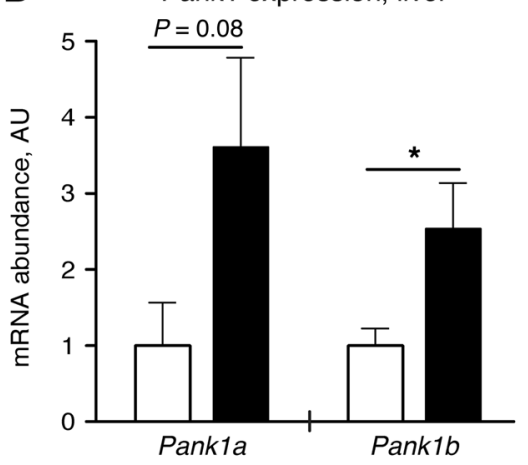

C
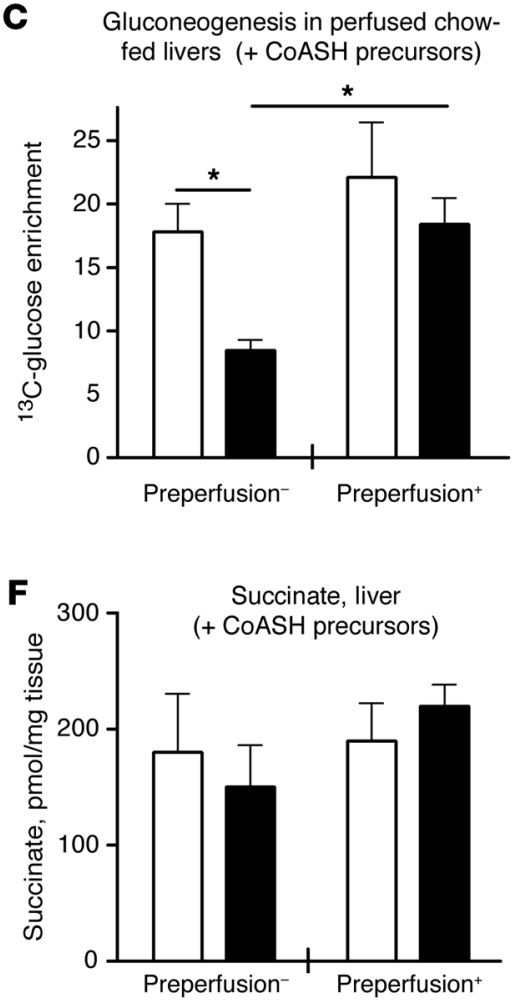

D
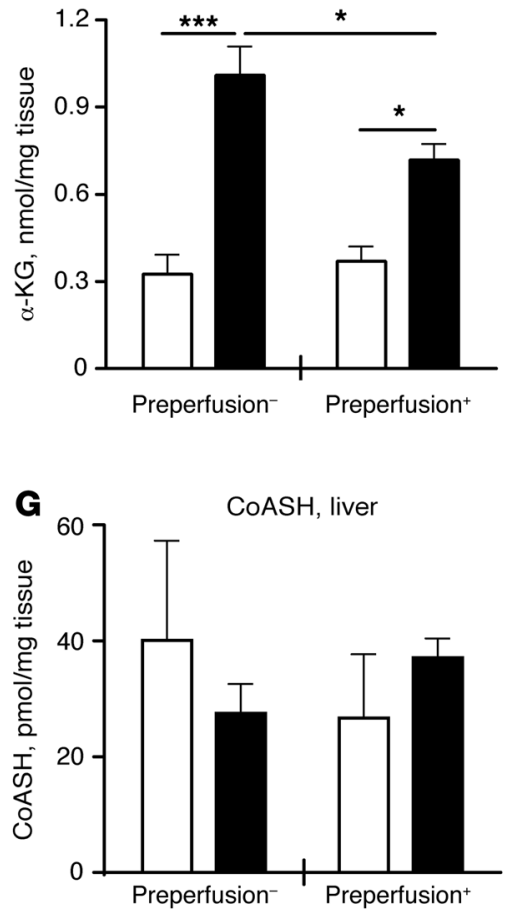

$\alpha-K G$, liver (+ CoASH precursors)
E
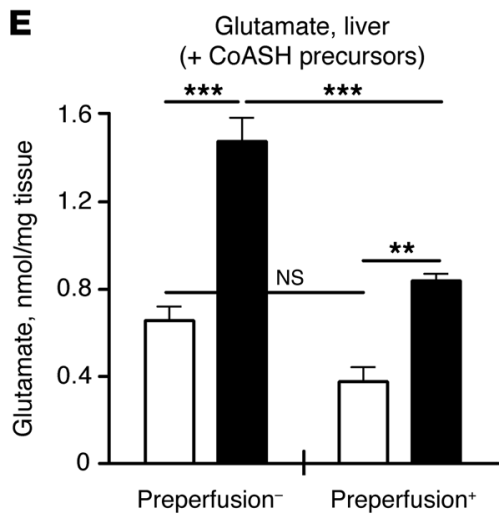

$\square$ Control

ASO

HMGCS2

ASO

Figure 7. Replenishing CoASH precursors restores gluconeogenesis and TCA cycle intermediate abnormalities in the livers of ketogenesis-insufficient mice. (A) CoASH (pmol/mg tissue) concentrations in the livers of unperfused standard chow diet-fed ASO-treated mice or in livers perfused with the indicated substrates. $n=3-8$ /group. (B) Pantothenate kinase $1 \mathrm{a}$ and $1 \mathrm{~b}$ (Pank1a and Pank1b) relative mRNA abundance in the livers of standard chow diet-fed ASO-treated mice. $n=8-10 /$ group. (C) Cluconeogenesis in perfused livers of standard chow diet-fed ASO-treated mice perfused with either [ $\left.{ }^{13} \mathrm{C}\right]$ lactate, $\left[{ }^{13} \mathrm{C}\right]$ pyruvate, octanoic acid, cysteine, and pantothenic acid for 15 minutes (Preperfusion-) or preperfused with CoASH precursors for 45 minutes with unlabeled lactate, pyruvate, cysteine, and pantothenic acid followed by 15 minutes of perfusion with $\left[{ }^{13} \mathrm{C}\right]$ lactate, $\left[{ }^{13} \mathrm{C}\right]$ pyruvate, octanoic acid, cysteine, and pantothenic acid. (D) $\alpha$-KG (nmol/mg tissue), (E) glutamate (nmol/mg tissue), (F) succinate (pmol/mg tissue), and (G) CoASH (pmol/mg tissue) concentrations in the same livers as in C. $n=5-7 /$ group. ${ }^{*} P<0.05,{ }^{* *} P<0.01,{ }^{* *} P<0.001$, by 2 -way ANOVA.

Ketogenic insufficiency increases acyl-CoA synthesis. Abnormal hepatic glucose metabolism in HFD-fed ketogenesis-insufficient animals suggested reprogramming of intermediary metabolism. Because the major conduits for acetyl-CoA in hepatic mitochondria include: (a) ketogenesis, (b) transport to the cytoplasm via the citrate shuttle to serve as a substrate for sterol or fatty acid synthesis, (c) terminal oxidation in the TCA cycle, or (d) ultimate conversion to acetylcarnitine (19), we performed 3 independent experiments to test the hypothesis that insufficient ketogenesis stimulates the procession of acetyl-CoA through the latter 3 nonketogenic pathways. First, to determine whether the acetyl-CoA fate was altered in hepatic mitochondria of ketogenesis-insufficient mice, we performed respiration studies on isolated hepatic mitochondria from ASO-treated animals fed a standard low-fat chow diet. While respiration rates using fatty acids (palmitoyl-Lcarnitine or octanoate) as oxidative substrates were not impaired 

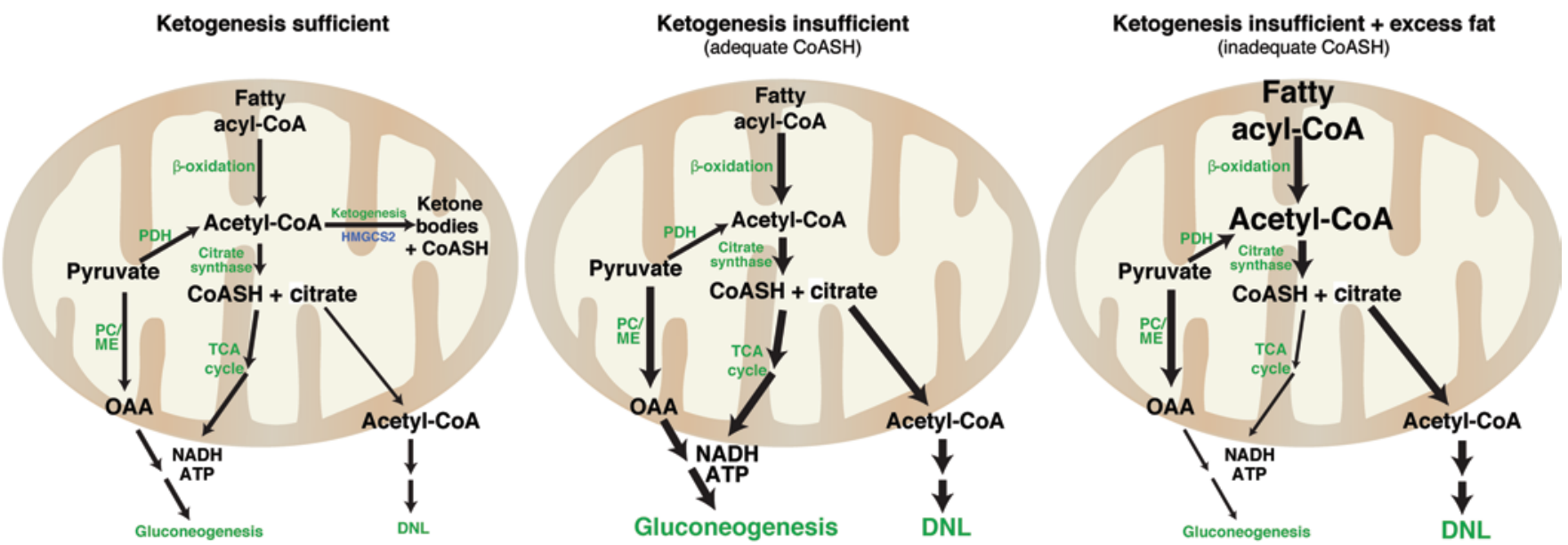

Figure 8. Model of hepatic maladaptation to ketogenic insufficiency. Under homeostatic conditions (left panel), mitochondrial acetyl-CoA can be channeled to ketogenesis, terminal oxidation in the TCA cycle, or exported to the cytoplasm for DNL. In the setting of ketogenic insufficiency (middle panel), DNL and gluconeogenesis from pyruvate are increased. Loss of the ketogenic conduit stimulates increased acetyl-CoA disposal through the TCA cycle, increasing gluconeogenesis and export to the cytoplasm for DNL. These changes partly reflect the alterations encountered in NAFLD, in which the liver exhibits increased esterification to and lipolysis from lipid droplets, increased $\beta$-oxidation of fatty acids, increased terminal oxidation, and increased gluconeogenesis, but diminished ketogenesis relative to the availability of fat. In the extreme circumstance of ketogenic insufficiency and a high-fat load (right panel), $\beta$-oxidation-derived acetyl-CoA sequesters CoASH. This disrupts the TCA cycle, and in the setting of increased DNL, ultimately triggers hepatic injury and inflammation. Arrow thicknesses reflect relative changes through enzymatic reactions among panels rather than between reaction pathways within a panel. While proportional contributions of pyruvate carboxylase (PC) and PDH fluxes to the pyruvate fate are dynamic in states of feeding and fasting, both fluxes occur simultaneously in both physiological states $(86,87)$ and are likely to be influenced by insufficient ketogenesis. ME, malic enzyme.

in hepatic mitochondria isolated from ketogenesis-insufficient animals (data not shown), oxygen consumption using pyruvate alone was markedly impaired: respiratory rates were diminished $31 \%$ in state 2 (basal proton leak), $62 \%$ in state 3 (ADP-stimulated), $49 \%$ in state 4 (ATP synthase-inhibited), and 65\% during uncoupled (maximal) respiration (Figure 4A). These results suggested relatively impaired pyruvate oxidation in ketogenesis-insufficient mice. Pyruvate dehydrogenase (PDH), the enzyme that decarboxylates pyruvate to form acetyl-CoA for terminal oxidation in the TCA cycle, is inhibited by increased acetyl-CoA concentrations (35). The addition of anaplerotic malate, which can facilitate acetyl-CoA export as citrate upon its conversion to oxaloacetate, normalized the capacity of hepatic mitochondria isolated from ketogenesis-insufficient mice to oxidize pyruvate (Figure 4B). Independent respiration studies using malate alone revealed minimal oxygen consumption that did not differ between groups (data not shown). These results suggest that while the respiratory function of isolated mitochondria from ketogenesis-insufficient mice is intact, an anaplerotic substrate is required to facilitate cytoplasmic export of excess acetyl-CoA as citrate to relieve inhibition of pyruvate oxidation.

Second, we quantified circulating acylcarnitine concentrations and observed that short- and medium-chain acylcarnitine concentrations, but not those of long-chain acylcarnitines, were significantly increased in HMGCS2 ASO-treated mice compared with controls fed either a $40 \%$ or $60 \%$ HFD, but not a standard low-fat chow diet (Figure 4, C and D; See Supplemental Tables 1-3 for full acylcarnitine profiles for chow-fed, $40 \%$ HFD-fed, and $60 \%$ HFD-fed mice). These results suggest that ketogenic insufficiency is unlikely to cause an overt impairment of $\beta$-oxidation, but that the supply of short-chain acyl-CoAs exceeds the capacity of the TCA cycle to dispose of them. Nonetheless, carnitine esters provide another mechanism for short- and medium-chain acylCoA disposal through nonketogenic mechanisms.

A third line of investigation comprehensively profiled the fate of acetyl-CoA in an unbiased manner. mRNA abundances of key encoded mediators of de novo lipogenesis (DNL) were increased in the livers of ketogenesis-insufficient animals, including significant increases in Srebp1c, Chrebp1, and Scd2, and strong trends toward increases in Fasn and Accl (Figure 5A). To map the full scope of the metabolic fates of acetyl-CoA, we perfused the livers of standard chow diet-fed ketogenesis-insufficient and control animals with a buffer containing $\left[{ }^{13} \mathrm{C}\right]$ pyruvate (and its redox partner $\left[{ }^{13} \mathrm{C}\right]$ lactate) for 15 minutes and analyzed extracts of these samples with a liquid chromatography/mass spectrometry-based (LC/MS-based) untargeted metabolomics platform $(36,37)$. We used $\left[{ }^{13} \mathrm{C}\right]$ pyruvate to generate a mitochondrial pool of labeled $\left[{ }^{13} \mathrm{C}\right]$ acetyl-CoA, whose downstream fates could then be assayed by detecting ${ }^{13} \mathrm{C}$ enrichment in metabolites using LC/MS, comparing metabolite abundances in ketogenesis-insufficient animals versus those in controls. This analysis revealed that ketogenic insufficiency in the livers of mice fed a standard chow diet resulted in altered levels of 495 features (i.e., peaks in the LC/MS data) of a total of 35,506 detected (fold-change $>20, P$ value $<0.01$; Figure $5 \mathrm{~B}$ and Supplemental Table 4). Remarkably, all but 3 of these 495 features were upregulated in the livers from ketogenesis-insufficient mice relative to those detected in control livers, suggesting that the vast majority of revealed features can be attributed to alterations of metabolite pool sizes rather than the emergence of new fates for $\left[{ }^{13} \mathrm{C}\right]$ pyruvate.

Given the alterations we identified in mRNAs of DNL mediators, metabolites in the fatty acid elongation pathway were of particular interest. Thus, we searched all features of ${ }^{13} \mathrm{C}$-labeled 
acyl-CoA species produced in the fatty acid elongation pathway described in the Kyoto Encyclopedia of Genes and Genomes (KEGG) $(38,39)$ and identified 14 features whose mass-to-charge value matched 1 or more of these species (Supplemental Table 5). The summed ion count of each of these acyl-CoA groups, representing the total abundance of a species in all of its observed labeled forms, was markedly increased in HMGCS2-deficient livers, suggesting increased flux through the DNL pathway (Figure 5, $\mathrm{C}$ and D). To confirm that these identified acyl-CoA species were not differentially labeled by $\left[{ }^{13} \mathrm{C}\right]$ pyruvate, bioinformatics analysis using software that we recently developed (40) revealed that these compounds were not labeled differently in ketogenesis-insufficient animals compared with those in controls, again supporting that augmented acyl-CoA pools cannot simply be attributed to increased labeling, but instead indicate increased pool sizes. Moreover, terminal oxidation of $\left[{ }^{13} \mathrm{C}\right]$ pyruvate in the TCA cycle was relatively diminished in the livers of ketogenesis-insufficient animals, as revealed by quantification of the fractional ${ }^{13} \mathrm{C}$ enrichment of glutamate from $\left[{ }^{13} \mathrm{C}\right]$ pyruvate by NMR $\left(12.8 \pm 1.9 \%{ }^{13} \mathrm{C}\right.$ enrichment of glutamate vs. $20.1 \pm 2.7 \%$ in controls, $n=7-8$ /group, $P<0.05$; Figure $5 \mathrm{E}) ;{ }^{13} \mathrm{C}$ enrichment of glutamate serves as a quantitative surrogate for $\left[{ }^{13} \mathrm{C}\right]$ acetyl-CoA terminal oxidation (41). However, we found that steady-state acetyl-CoA concentrations in whole liver extracts were not altered in ketogenesis-insufficient animals (Figure 5F). Collectively, these findings indicate that insufficient ketogenesis triggers a redistribution of the total mitochondrial acetylCoA pool toward export and de novo lipid synthesis.

Ketogenic insufficiency sequesters free CoASH. To better understand the shift from hyperglycemia in chow-fed ketogenesis-insufficient mice to hypoglycemia upon high-fat feeding, we quantified gluconeogenesis from $\left[{ }^{13} \mathrm{C}\right]$ pyruvate in the presence or absence of octanoic acid in perfused livers of ASO-treated mice fed a standard low-fat chow diet. Octanoic acid is a medium-chain fatty acid that enters the mitochondrial matrix independently of carnitine palmitoyltransferase 1 (CPT1) and rapidly stimulates mitochondrial $\beta$-oxidation and gluconeogenesis (19). Consistent with the observation of hyperglycemia in standard chow diet-fed HMGCS2 ASO-treated mice (Supplemental Figure 2G), we found that basal gluconeogenesis from pyruvate in the absence of octanoic acid was increased in the livers of ketogenesis-insufficient animals $\left(15.2 \pm 2.1 \%{ }^{13} \mathrm{C}\right.$ enrichment of glucose vs. $9.0 \pm 1.0 \%$ in controls, $n=7-8$ /group, $P=0.015$; Figure $6 \mathrm{~A}$ ). Because total hepatic glucose concentrations did not differ between groups (Figure 6B), the increased enrichment reflects increased production from pyruvate. As expected, the addition of unlabeled octanoic acid to the perfusion buffer stimulated gluconeogenesis in the livers of control animals (Figure 6A, white bars), but in contrast, HMGCS2 ASO-treated livers perfused with octanoic acid did not increase gluconeogenesis and, in fact, exhibited decreased ${ }^{13} \mathrm{C}$-glucose enrichment compared with that seen in control livers $(11.8 \pm 1.7 \%$ ${ }^{13} \mathrm{C}$ enrichment of glucose vs. $17.6 \pm 1.3 \%$ in controls, $n=7-8$ /group, $P=0.018$; Figure 6A), without altering total glucose pools (Figure $6 \mathrm{~B})$. We observed the inability of octanoic acid to stimulate glucose production in HMGCS2 ASO-treated livers despite increased mRNA abundances of Ppara, Aco, Cpt1a, Ppargc1a, Pck1, and Me2 and normal mRNA abundances of Acadm, Fgf21, and G6Pc in liver (Figure 6C), suggesting that a metabolic mechanism, rather than insufficient expression of the enzymatic mediators of fatty acid oxidation and gluconeogenesis, underlies the observed defect in fatty acid-stimulated glucose production in the setting of ketogenic insufficiency.

Because the induction of gluconeogenesis by fatty acids is dependent on the NADH and ATP generated through the TCA cycle $(16,42,43)$, we hypothesized that the failure of mitochondrial fatty acids to stimulate gluconeogenesis in the absence of ketogenesis could be mechanistically linked to a failure to couple $\beta$-oxidation of fatty acids to their terminal oxidation via the TCA cycle. To determine whether there were abnormalities of TCA cycle function in the livers of HMGCS2 ASO-treated mice, we used NMR to quantify TCA cycle intermediate-pool concentrations in perfused livers of control and HMGCS2 ASO-treated mice. While tissue $\alpha$-ketoglutarate $(\alpha-K G)$ concentrations were normal in the livers perfused in the absence of octanoate, inclusion of this fatty acid in the perfusion buffer increased concentrations of $\alpha$-KG by 2 -fold in HMGCS2 ASO-treated livers $(0.75 \pm 0.08 \mathrm{nmol} / \mathrm{mg}$ tissue vs. 0.34 $\pm 0.08 \mathrm{nmol} / \mathrm{mg}$ tissue in control livers perfused with octanoate, $n=7-8$ /group, $P=0.0032$; Figure 6D). Perfusion with octanoic acid also increased hepatic concentrations of glutamate, an equilibrium partner of $\alpha-K G$, by 2 -fold, but significantly decreased hepatic succinate concentrations by $43 \%$ in HMGCS2 ASO-treated livers (99.9 $\pm 12.9 \mathrm{pmol} / \mathrm{mg}$ tissue vs. $162.8 \pm 20.1 \mathrm{pmol} / \mathrm{mg}$ tissue in controls, $P<0.01, n=7-8$ /group; Figure 6, E and F). These derangements of TCA cycle intermediate concentrations were not linked to redox potential alterations, as $\mathrm{NAD}^{+}, \mathrm{NADH}, \mathrm{NADt}$ concentrations, and $\mathrm{NAD}^{+} / \mathrm{NADH}$ ratios in ketogenesis-insufficient livers perfused in the absence (Figure $6 \mathrm{G}$ ) or presence (Figure $6 \mathrm{H}$ ) of octanoate were not different from those of control animals. Taken together, these data suggest that ketogenic insufficiency disrupts TCA cycle homeostasis and gluconeogenesis through mechanisms independent of altered redox potential.

The NMR findings from perfused livers of ketogenesis-insufficient mice suggest a block at the TCA cycle reaction catalyzed by the $\alpha-K G$ dehydrogenase complex (OGDC). Since intrinsic OGDC activity was normal in isolated mitochondrial respiration assays using glutamate as a substrate (data not shown), the redox potential was normal in perfused livers, and oxidative decarboxylation of $\alpha-\mathrm{KG}$ to succinyl-CoA requires free $\mathrm{CoASH}$, we tested the hypothesis that CoASH becomes limiting in ketogenesisinsufficient livers exposed to excess fat by quantifying $\mathrm{CoASH}$ concentrations in unperfused and perfused livers of ASO-treated mice. While HMGCS2 ASO treatment did not alter CoASH concentrations in unperfused livers of standard chow diet-fed mice or in livers perfused in the absence of octanoate, hepatic $\mathrm{CoASH}$ concentrations were decreased by $60 \%$ in HMGCS2 ASO-treated livers perfused with octanoic acid $(40.7 \pm 14.4 \mathrm{pmol} / \mathrm{mg}$ tissue vs. $106.6 \pm 24.3 \mathrm{pmol} / \mathrm{mg}$ tissue in controls, $P=0.035, n=8 /$ group; Figure 7A). The fatty acid-induced depletion of CoASH observed in HMGCS2 ASO-treated livers occurred despite normal expression of Pank1a and increased expression of Pank1b (1.0 \pm 0.02 vs. $2.5 \pm 0.6, P=0.04, n=8-10 /$ group), whose products phosphorylate pantothenic acid in the first step of de novo CoASH biosynthesis (Figure 7B). Consistent with the octanoate-induced derangements of TCA cycle intermediates and CoASH depletion in livers of standard chow diet-fed HMGCS2 ASO-treated mice, 
unperfused livers of HMGCS2 ASO-treated mice fed a $60 \%$ HFD displayed increased glutamate concentration (2.6 \pm 0.4 vs. $1.1 \pm 0.1 \mathrm{nmol} / \mathrm{mg}$ tissue in controls, $P=0.018, n=4-5 /$ group), a trend toward decreased succinate concentration, and decreased hepatic CoASH concentration $(28.4 \pm 11.5 \mathrm{pmol} \mathrm{CoASH} / \mathrm{mg}$ tissue vs. $103.1 \pm 32.6$ in controls, $P=0.049, n=8$ /group; Supplemental Figure $6, A-C)$. Taken together, these results suggest that ketogenic insufficiency in the setting of high-fat delivery depletes free CoASH and thereby impairs TCA cycle function, which further inhibits entry of acetyl-CoA and also favors increased accumulation of short-chain acylcarnitines.

To determine whether supplementation of the CoASH precursors pantothenic acid (vitamin $\mathrm{B}_{5}$ ) and cysteine could restore glucose production and normalize TCA cycle intermediate concentrations in HMGCS2 ASO-treated livers, we perfused the livers of HMGCS2-deficient and control animals with exogenous octanoate and CoASH precursors. While inclusion of pantothenic acid and cysteine with $\left[{ }^{13} \mathrm{C}\right]$ lactate, $\left[{ }^{13} \mathrm{C}\right]$ pyruvate, and unlabeled octanoic acid during a 15-minute perfusion failed to normalize gluconeogenesis in HMGCS2 ASO-treated livers (Figure 7C, left), prolonged repletion of CoASH precursors by perfusing independent livers with pantothenic acid and cysteine for 45 minutes prior to perfusion with $\left[{ }^{13} \mathrm{C}\right]$ lactate and $\left[{ }^{13} \mathrm{C}\right]$ pyruvate, unlabeled octanoic acid, pantothenic acid, and cysteine for 15 minutes normalized ${ }^{13} \mathrm{C}$-glucose enrichment (Figure 7C, right). Total hepatic glucose concentrations did not differ between control and HMGCS2 ASO-treated livers in either perfusion experiment (Supplemental Figure 7). Moreover, preperfusion with $\mathrm{CoASH}$ precursors attenuated the expansion of the $\alpha-K G$ and glutamate pools in HMGCS2 ASO-treated livers, with preperfused HMGCS2 ASO-treated livers exhibiting a 29\% decrease in $\alpha-K G$ concentrations and a $43 \%$ decrease in glutamate concentrations compared with those in HMGCS2 ASO-treated livers that were not preperfused with CoASH precursors ( $n=5-7 /$ group, $P<0.05$ for $\alpha-\mathrm{KG}$, and $P<0.001$ for glutamate; Figure 7, D and E). Inclusion of pantothenic acid and cysteine also normalized succinate concentrations in the livers of HMGCS2 ASO-treated mice, irrespective of the length of the perfusion (Figure 7F). Finally, CoASH precursor supplementation with either method of perfusion normalized the steady-state concentrations of free CoASH in the livers of ketogenesis-insufficient mice compared with those in control livers (Figure 7G). Taken together, these results mechanistically link the HFD-induced hypoglycemia and fat-induced impairment of hepatic gluconeogenesis we observed in ketogenesis-insufficient mice to CoASH depletion and inhibition of the $\alpha$-KG dehydrogenase reaction of the TCA cycle.

\section{Discussion}

Hepatic ketogenesis is activated when fatty acids are plentiful, carbohydrates are in short supply, and/or circulating insulin concentrations are low (17-21). This spillover pathway converts $\beta$-oxidation-derived acetyl-CoA, produced in excess of the hepatocyte's own energy needs, into ketone body intermediates, thus diverting carbon away from the hepatic TCA cycle and providing extrahepatic tissues with a readily oxidized fuel source. This paradigm forms an "altruistic" model of ketone body metabolism, in which the hepatocyte shares "precatabolized" energy obtained from fatty acids with other organs that may require it, particularly in states of diminished carbohydrate availability. However, this model neither accounts for the hepatocyte's need to support ketogenesis for its own metabolic homeostasis, nor considers the importance of basal hepatic ketogenesis in physiological states that are not considered "ketogenic" (i.e., carbohydrate restricted). Ours are the first studies to our knowledge to demonstrate a critical role for hepatic ketogenesis in the normal absorptive state and in prevention of metabolic decompensation in the setting of overnutrition. We found that when ketogenic capacity is markedly impaired, an HFD triggers a cascade of events that culminates in hepatic injury and inflammation. These observations are underscored by our recent studies of germline SCOT-KO mice, which cannot terminally oxidize ketone bodies in any tissue. These mice exhibit hyperketonemic hypoglycemia and die within 48 hours of birth in a manner that phenocopies human sudden infant death syndrome (SIDS) (32). Despite the fact that SCOT is normally excluded from hepatocytes, livers of SCOT-KO mice develop abnormalities of hepatic fatty acid oxidation, pyruvate metabolism, redox potential, and even ketogenesis $(22,33)$. In stark contrast to the severe metabolic derangements and SIDS-like phenotype observed in neonatal SCOT-KO mice, mice that cannot oxidize ketone bodies selectively within neurons, cardiomyocytes, or skeletal myocytes, which comprise the 3 greatest consumers of ketone bodies, survive the neonatal period and starvation in adulthood (34). Together, these results indicate that coordination of ketogenesis and ketone body oxidation may be of greater importance to preserve the dynamic intermediary metabolic network in the liver than it is to provide energy to extrahepatic tissues.

Our data are consistent with a model (Figure 8) in which the metabolic consequences of ketogenic insufficiency occur along a continuum of maladaptive consequences. On a standard diet and in the absence of a high lipid load, the modest amount of acetylCoA generated from endogenous fats that would normally proceed through ketogenesis is instead terminally oxidized in the TCA cycle, generating the ATP and NADH to support increased gluconeogenesis from pyruvate, thereby predisposing to mild hyperglycemia. In addition, the total hepatic mitochondrial pool of acetyl-CoA, which is predominantly derived from $\beta$-oxidation of acyl-CoAs and by decarboxylation of pyruvate, is maintained at a homeostatic concentration by eventual conversion to acetylcarnitine and by exportation as citrate for synthesis of de novo lipids. Given that gluconeogenesis is indirectly stimulated by mitochondrial acetyl-CoA through allosteric activation of pyruvate carboxylase (44), adult-onset loss of ketogenesis may reset the basal rate of gluconeogenesis through a shift toward increased mitochondrial acetyl-CoA. Therefore, even in the nonlipolytic absorptive state, in which dietary carbohydrates are abundant, hepatic ketogenesis influences glycemia and hepatic lipid metabolism through modulation of acetyl-CoA fates. These experimental conditions, in which ketogenesis is severely deficient but exogenous fat delivery is low, may be representative of more clinically relevant states in which ketogenesis is modestly suppressed, but exogenous fat delivery (from intake) is elevated. Acetyl-CoA metabolism has recently emerged as a key regulator of numerous cellular processes and signaling pathways, and acetylCoA has different roles depending on its site of synthesis or accumulation. Cytosolic and/or nuclear acetyl-CoA regulate protein 
acetylation $(45,46)$, autophagy $(47,48)$, and histone acetylation and subsequent transcriptional changes $(49,50)$. Future experiments will explore the scope of signaling consequences of insufficient ketogenesis, how altered acetyl-CoA metabolism may mediate those effects, and how discrete acetyl-CoA pools target distinct fates based on the original source of acetyl-CoA. Because the retention time window harboring the majority of dysregulated LC/MS features in the livers of ketogenesis-insufficient animals included a large number of lipophilic molecules, these approaches may reveal previously unsuspected connectivity among hepatic ketogenesis, acetyl-CoA, lipid metabolism, and cell signaling.

The convergence of ketogenic insufficiency with either acute delivery of fatty acids or chronic exposure to a "nonketogenic" (not carbohydrate-restricted) HFD results in additional metabolic sequelae (Figure 8 , right) that uncouple increased fat availability from increased gluconeogenesis through mechanisms that can be linked to sequestration of free $\mathrm{CoASH}$, a critical by-product of ketogenesis. Therefore, despite presumably increased allosteric activation of pyruvate carboxylation, gluconeogenesis becomes impaired through mechanisms that can be linked to a diminished availability of CoASH. CoASH liberated by ketogenesis is critical in states of high-fat delivery, in part by serving as a substrate for the $\alpha-K G$ dehydrogenase reaction, to support homeostatic TCA cycle function, which in hepatocytes is a key regulator of gluconeogenesis. Intriguingly, the total hepatic triacylglycerol pool did not expand in the livers of HFD-fed ketogenesis-insufficient animals compared with that observed in controls, suggesting either relative limitation of substrate (e.g., glycerol), impairment of cytoplasmic acylglycerol transferase or phosphatidate phosphatase activity, or entry of acyl chains into other synthetic pathways.

Ketogenesis-insufficient mice fed an HFD developed steatosis equivalent to that seen in controls, but only ketogenesis-insufficient mice developed severe inflammation, suggesting that of the 2 major NAFLD subtypes, simple steatosis and NASH, impaired ketogenesis may be an important determinant of NASH (1). Other forms of hepatocellular injury are also associated with decreased CoASH concentrations. In acute acetaminophen toxicity, CoASH levels decrease simultaneously with decreasing HMGCS2 enzymatic activity (51, 52). Potentially fatal valproic acid therapy-induced hepatic dysfunction, which is associated with impaired $\beta$-oxidation of fatty acids and ketogenesis due to sequestration of CoASH into poorly metabolized valproyl CoA, can be prevented by administration of $\mathrm{CoASH}$ precursors $(53,54)$. In rodents, hepatic CoASH concentrations decrease in response to an HFD (55), while the concentration of pantothenic acid actually increases (56), suggesting that hepatic CoASH homeostasis is dysregulated in obesity. De novo CoASH synthesis is required for life in mice, and impaired CoASH synthesis is associated with fasting-induced hepatic steatosis $(57,58)$. CoA sequestration, toxicity, or redistribution (CASTOR) encompasses hereditary and acquired diseases of impaired $\mathrm{CoASH}$ liberation, including deficiencies of hepatic ketogenesis (59). Despite the increasing burden of evidence for the contribution of CoASH homeostasis to hepatic function, the role of therapies that support de novo CoASH synthesis in obesity and NAFLD remains relatively unexplored.

HMGCS2 has been proposed to possess a "moonlighting" role as a transcriptional regulator that translocates to the nucleus and serves as a coactivator for a master transcriptional regula- tor of fatty acid oxidation, peroxisome proliferator-activated receptor $\alpha(\operatorname{PPAR} \alpha)(60,61)$. In at least 1 immortalized hepatoma cell line, HMGCS2 expression was required for fatty acid oxidation (62). In contrast, our observations reveal a robust induction of several classical PPAR $\alpha$ targets in the absence of hepatic HMGCS2, and 2 lines of evidence support robust fatty acid oxidation in the livers of HMGCS2-deficient mice: (a) long-chain acylcarnitines did not accumulate, and (b) the contribution of pyruvate to the acetyl-CoA oxidized in the TCA cycle was relatively diminished. Moreover, the increased gluconeogenesis we observed in the livers of ketogenesis-insufficient animals under low-fat-diet conditions strongly suggests normal or elevated TCA cycle flux. Together, these data indicate an increase in the relative contribution of endogenous fatty acids to the TCA cycle and are consistent with metabolic flux that is driven primarily by the principles of mass action and enzymatic allostery, with coordinated responses at the level of gene expression that reflect adaptations to diminished disposal of acetyl-CoA through ketogenesis. Whether HMGCS2 serves as a PPAR $\alpha$ coactivator in vivo remains to be determined, as does whether the prospective ligands produced via DNL in ketogenesis-insufficient animals serve as potential PPAR $\alpha$ activators (63).

Genome-wide association and exome sequencing studies have revealed relationships between numerous genes encoding mediators of lipid metabolism and NAFLD/NASH $(64,65)$. Variations in the genes encoding ketogenic mediators, including HMGCS2, HMG-CoA lyase, and $\beta \mathrm{OHB}$ dehydrogenase, have not yet emerged as independent predictors of liver pathology or diabetes. While HMGCS2 deficiency is very rare in humans, total HMGCS2 enzymatic deficiency is associated with pediatric hypoketonemic hypoglycemia and hepatic steatosis (66-71). Importantly, our studies of neonatal mice revealed that partial loss of HMGCS2 activity caused marked hepatic steatosis vastly out of proportion to the diminution in neonatal ketosis, but did not result in neonatal hypoglycemia or failure to thrive. These findings raise the possibility that genetic polymorphisms yielding insidious and subtle ketogenic defects could latently predispose to fatty liver disease and attest to the critical fine-tuning role that hepatic ketogenesis plays in the regulation of hepatic glucose and lipid metabolism.

No current pharmacological therapies directly treat NAFLD or NASH, which are managed instead through lifestyle modifications such as weight loss and treatment of dyslipidemia and hyperglycemia (72). A variety of agents are at various stages of investigation, including compounds targeting oxidative stress, nuclear receptor activators, insulin sensitizers, modifiers of dyslipidemias, and immunomodulatory agents $(3,6)$. Ketogenesis has not yet been considered as a therapeutic target. Obese humans and mice exhibit diminished whole-body ketone body turnover $(26,29)$. Furthermore, circulating ketone body concentrations are generally decreased in obese humans $(24,25,27)$ and serve as predictive biomarkers for conversion to type 2 diabetes in patients with impaired fasting glucose (73). Compared with BMI-matched individuals, obese patients with NAFLD exhibit increased hepatic glucose production and TCA cycle flux without augmented ketogenesis (28). DNA methylation, nuclear receptor-mediated transcriptional activation, and reversible succinylation, acetylation, 
and phosphorylation all exert multitiered transcriptional and posttranslational regulation of Hmgcs2 expression and HMGCS2 enzymatic activity to coordinate ketogenesis during diverse physiologic contexts $(17,74-78)$. Pharmacological approaches that regulate enzymatic mediators of lysine deacylation (45) may represent a promising avenue for modulating HMGCS2 and ketogenesis, which may serve as a novel therapeutic target in fatty liver disease and obesity.

\section{Methods}

Further information can be found in the Supplemental Methods.

Animals. All adult mice studied were males on a C57BL/6N X C57BL/6J hybrid background. For neonatal experiments, both sexes were studied. Unless otherwise noted, mice were maintained on a standard low-fat chow diet, in which $13 \%$ of the calories were from fat, $25 \%$ from protein, and $62 \%$ from carbohydrates (LabDiet 5053), and were given autoclaved water ad libitum. Lights were off between 1800 and 0600 in a room maintained at $22^{\circ} \mathrm{C}$. For all adult mouse experiments, mice were housed on sawdust bedding in groups of 4 to 5 . ASO treatment was initiated in 6-week-old mice by i.p. injection $(25 \mathrm{mg} / \mathrm{kg}$ ) with murine Hmgcs2-targeted ASOs (ISIS 191229; 5'-CTGTTTGTCACTGCTGGATG) or scrambled sequence control ASOs (ISIS 141923; 5'-CCTTCCCTGAAGGTTCCTCC) biweekly for 4 weeks. For HFD studies, after 2 weeks of ASO treatment, mice were maintained for 8 weeks on either an HFD, in which $60 \%$ of calories were from fat, $20 \%$ from protein, and $20 \%$ from carbohydrates (D12492; Research Diets), or, in separate cohorts, a diet (110290; Harlan Teklad) in which $40.7 \%$ of calories were from fat (lard and milk fat, $52 \%$ saturated, $41 \%$ monounsaturated, and $7 \%$ polyunsaturated [0\% trans] fatty acids), $19 \%$ from protein, and $40.3 \%$ from carbohydrates (sucrose, $183 \mathrm{~g} / \mathrm{kg}$ and cornstarch, $140 \mathrm{~g} / \mathrm{kg}$ ), during which time biweekly ASO administration continued. For the neonatal experiments, ASOs were administered $(25 \mathrm{mg} / \mathrm{kg})$ s.c. daily, beginning on the second day of life and until P12. Pups were marked on the abdomen daily with a permanent marker to enable longitudinal monitoring of body weight and blood glucose. Marking also enabled control and HMGCS2 ASOs to be administered to different pups within the same litter, thus minimizing inter-litter variance of metabolic parameters.

Measurements of food intake, body weight, and body composition. Food intake was monitored beginning on day 1 of ASO treatment for each cage of mice. Food intake was measured biweekly for the duration of each experiment and normalized to the number of mice per cage and the number of days between measurements, which was always 3 or 4 days. Mice were also weighed biweekly at the onset of all experiments. Body weight and body composition were recorded following a 4-hour fast (1000-1400), after which food was returned immediately. The percentage of body fat and lean body mass was quantified in awake adult animals using an EchoMRI instrument (Echo Medical Systems).

Plasma metabolite quantification. Serum and blood metabolic parameters were measured in samples collected following a 4-hour fast, as described previously (31).

Tissue metabolite quantification. Hepatic TAG concentrations were quantified biochemically using a Folch extract of liver, as described previously (79). Tissue $\mathrm{CoASH}, \mathrm{NAD}^{+}$, and NADH concentrations were measured in freeze-clamped and biopulverized liver tissue. For CoASH, approximately $75 \mathrm{mg}$ of tissue was homogenized using a glass-on-glass dounce in $\times 10$ volume of ice-cold deionized water. Homogenates were spun at $15,000 \mathrm{~g}$ for 20 minutes at $4^{\circ} \mathrm{C}$. Supernatants were transferred to clean tubes on ice and were then dehydrated using a rotary speed vacuum. Tissue pellets were resuspended to $2 \mathrm{mg} / \mu \mathrm{l}$, and $20 \mathrm{mg}$ of tissue $(10 \mu \mathrm{l})$ were loaded into a 96-well plate for CoASH and long-chain acyl-CoA concentrations using an enzyme-linked colorimetric assay (BioVision). $\mathrm{NAD}^{+}(\mathrm{H})$ concentrations were measured using an enzyme-cycling colorimetric assay (BioVision).

Histology. Immediately following sacrifice, liver specimens were collected and fixed in 10\% neutral buffered formalin (Fisher Scientific) or cryopreserved in optimal cutting temperature compound (O.C.T.; Tissue-Tek).

Gene expression analysis. Quantification of gene expression was performed by real-time reverse-transcriptase quantitative PCR using the $\Delta \Delta \mathrm{Ct}$ approach, as previously described (31), normalizing to Rpl32, using the primer sequences listed in Supplemental Table 6.

Immunoblotting. Immunoblots to detect HMGCS2 (rabbit antimHMGCS; Santa Cruz Biotechnology Inc.), HMGCS1 (rabbit antiHMGCS1; Thermo Fisher Scientific), and actin (rabbit anti-actin; Sigma-Aldrich) were performed as previously described (32).

Liver perfusions. Mice were fasted for 4 hours prior to perfusion, with the exception of mice that were perfused after an overnight fast as indicated in the Results. Ten minutes prior to each liver perfusion, mice received an i.m. injection of heparin (100 U). Mice were then anesthetized with $10 \mu \mathrm{l}$ of sodium pentobarbital (FatalPlus, $390 \mathrm{mg} / \mathrm{ml}$ ) administered i.p. Once fully anesthetized (after approximately 5 minutes), the abdomen was sprayed with $70 \%$ ethanol, and the mouse was placed on a surgical platform within a large reservoir to contain run-off buffer and body fluids. A transverse incision was made through the skin, fascia, and muscular layers of the lower abdomen. A lateral sagittal incision was made on each side of the body, exposing the abdominal contents. A second transverse incision was made inferiorly to the right kidney and toward the dorsal aspect of the mouse to allow the perfusion buffer and body fluids to drain from the abdomen. The portal vein was then exposed by gently moving the intestines laterally toward the left body wall. A suture needle was threaded under the portal vein and tied loosely. Next, the portal vein was cannulated with a 24-gauge catheter needle, the needle was withdrawn, and tubing with buffer was reconnected to the catheter. The abdominal aorta and inferior vena cava were cut, and the catheter was firmly tied into the portal vein. Finally, the beating heart was exposed by cutting through the diaphragm and thorax. The right atrium was cut to prevent recirculation of buffer to the liver and to terminate perfusion to the brain. All livers were perfused with an oxygenated Krebs-Henseleit bicarbonate buffer (118 mM NaCl, $25 \mathrm{mM} \mathrm{NaHCO}_{3}, 4.7 \mathrm{mM} \mathrm{KCl}, 0.4$ $\left.\mathrm{mM} \mathrm{KH}_{2} \mathrm{PO}_{4}, 2.5 \mathrm{mM} \mathrm{CaCl}_{2}, 1.22 \mathrm{mM} \mathrm{MgSO}_{4}-7 \cdot \mathrm{H}_{2} \mathrm{O}, \mathrm{pH} 7.4\right)$ and warmed to $37^{\circ} \mathrm{C}$ with a counter-current heat-exchange circuit and a recirculating water bath at a rate of $8 \mathrm{ml} /$ minute using a peristaltic pump for 15 minutes, unless otherwise noted. At the end of the perfusion, the liver was freeze-clamped and rapidly frozen in a bath of liquid nitrogen. Tissue was stored at $-80^{\circ} \mathrm{C}$ until further processing. For measurements of ketogenesis in perfused livers, the buffers contained sodium $\left[1,2,3,4-{ }^{13} \mathrm{C}_{4}\right]$ octanoate $(0.2 \mathrm{mM})$, sodium lactate $(1.5 \mathrm{mM})$, and sodium pyruvate $(0.15 \mathrm{mM})$. For all measurements 
of gluconeogenesis, the livers were perfused with sodium $\left[3-{ }^{13} \mathrm{C}\right]$ lactate $(1.5 \mathrm{mM})$ and sodium $\left[3{ }^{-13} \mathrm{C}\right]$ pyruvate $(0.15 \mathrm{mM})$, and in a subset of these experiments, unlabeled sodium octanoate $(0.2 \mathrm{mM})$ was included in the buffer (stable isotopes were obtained from Cambridge Isotope Laboratories). For the CoASH repletion experiments, unlabeled pantothenic acid and L-cysteine were included in the perfusion buffer at $0.15 \mathrm{mM}$ and $0.1 \mathrm{mM}$, respectively, in addition to sodium $\left[3-{ }^{13} \mathrm{C}\right]$ lactate $(1.5 \mathrm{mM})$, sodium $\left[3-{ }^{13} \mathrm{C}\right]$ pyruvate $(0.15 \mathrm{mM})$, and unlabeled sodium octanoate $(0.2 \mathrm{mM})$. The livers preperfused with CoASH precursors received unlabeled pantothenic acid ( 0.15 $\mathrm{mM})$, Cys $(0.1 \mathrm{mM})$, sodium lactate $(1.5 \mathrm{mM})$, and sodium pyruvate $(0.15 \mathrm{mM})$ for 45 minutes before being switched to a buffer containing pantothenic acid $(0.15 \mathrm{mM})$, cysteine $(0.1 \mathrm{mM})$, sodium $\left[3-{ }^{13} \mathrm{C}\right]$ lactate $(1.5 \mathrm{mM})$, sodium $\left[3-{ }^{13} \mathrm{C}\right]$ pyruvate $(0.15 \mathrm{mM})$, and unlabeled sodium octanoate $(0.2 \mathrm{mM})$ for 15 minutes.

NMR-based quantitative substrate fate mapping. Neutralized perchloric acid tissue extracts were prepared and profiled using ${ }^{13} \mathrm{C}$-edited proton NMR, as described previously $(32,33)$.

Tandem MS analysis of blood acylcarnitines. Carnitine esters were measured by scanning for the precursors of the common $\mathrm{m} / z 85$ carnitine fragment in a reversed-phase LC protocol coupled to tandem MS (MS/MS), as described previously (80).

Untargeted LC/MS profiling of perfused liver extracts. Livers from control- and HMGCS2 ASO-treated mice were perfused with sodium $\left[3-{ }^{13} \mathrm{C}\right]$ lactate $(1.5 \mathrm{mM})$ and sodium $\left[3-{ }^{13} \mathrm{C}\right]$ pyruvate $(0.15 \mathrm{mM})$ as described above, then snap-frozen and pulverized. Four replicates of each sample type consisting of 10 to $20 \mathrm{mg}$ of pulverized tissue were extracted with $1 \mathrm{ml}$ of 2:2:1 acetonitrile $(\mathrm{ACN}) / \mathrm{methanol} /$ water, using the protocol previously described by Ivanisevic et al. (37). Briefly, samples were resuspended in solvent and subjected to repeated freeze-thaw cycles. Extracted metabolites were recovered through evaporation of the solvent and reconstituted in $100 \mu \mathrm{l}$ of 1:1 ACN/water for LC/MS analysis. Eight microliters of each extract was injected onto a Luna aminopropyl $3-\mu \mathrm{m}, 150-\mathrm{mm} \times 1.0-\mathrm{mm}$ internal-diameter column (Phenomenex) used in hydrophilic interaction liquid chromatography (HILIC) mode on an Agilent 1260 HPLC system. Mobile-phase compositions were: $\mathrm{A}=95 \%$ water, $5 \% \mathrm{ACN}, 10 \mathrm{mM}$ ammonium hydroxide, $10 \mathrm{mM}$ ammonium acetate, $\mathrm{pH} 9.5$; B = $95 \% \mathrm{ACN}, 5 \%$ water, with the gradient set at $100 \%$ B from 0 to 5 minutes, $100 \%$ to $0 \%$ B from 5 to 50 minutes, and $0 \%$ B from 45 to 50 minutes. The flow rate was $50 \mu \mathrm{l} /$ minute. MS detection in the range of 30 to $1,500 \mathrm{~m} / \mathrm{z}$ was performed on an Agilent 6540 quadrupole time-offlight (Q-TOF) instrument equipped with a Dual Agilent Jetstream electrospray ionization (ESI) source operating in negative mode. Source parameters were set at: gas temperature $=300^{\circ} \mathrm{C}$, drying gas $=9$ liters $/$ minute, nebulizer $=35 \mathrm{psig}$, sheath gas temperature $=$ $350^{\circ} \mathrm{C}$, sheath gas flow $=11$ liters $/$ minute, capillary voltage $=3,500$ $\mathrm{V}$, and nozzle voltage $=1,000 \mathrm{~V}$. Spectra were collected at a rate of $1 /$ second, corresponding to 8,133 transients/spectrum. The raw data were converted to mzXML files using the msconvert tool in the ProteoWizard software suite (81) and uploaded to XCMS Online (82) to generate the features table listing all detected ions and their aligned retention times (https://xcmsonline.scripps.edu; Public Shares Job ID 1027173) (83). The parameters used in XCMS Online are listed in Supplemental Table 4; $P$ values and fold-change cutoffs of 0.01 and 20, respectively, were applied.
The features table was then processed in $\mathrm{R}$ to search for features whose $m / z$ matched to species in the fatty acid elongation pathway as detailed in $\operatorname{KEGG}(38,39)$. Consideration was given for enrichment of ${ }^{13} \mathrm{C}$ labels in each species by grouping features with similar retention times ( $<0.2$-minute range) and whose $m / z$ values were offset from the mass of an unlabeled acyl-CoA species by whole-number multiples of the mass difference between ${ }^{12} \mathrm{C}$ and ${ }^{13} \mathrm{C}(1.00335$ $\mathrm{amu})$. Where multiple groups of such features, known as isotopologs, matched to a single acyl-CoA species, a selection of the single group to which the species was assigned was made based on the following criteria: (a) minimum of 3 isotopologs represented in the group; (b) statistically significant difference $(P<0.05$, by Student's $t$ test) in abundance between control and HMGCS2-deficient samples for at least 1 isotopolog in the group; and (c) proximity of the group's retention time to that of other groups assigned to acyl-CoAs, given that these species are all chemically similar and are expected to elute close to one another. Where a single group matched to multiple potential acyl-CoA species, all possible identities are listed in Supplemental Table 5, but for the plot in Figure 5D, the $978 \mathrm{~m} / \mathrm{z}$ group was assigned to tetredecanoyl-CoA due to the lower number of ${ }^{13} \mathrm{C}$ labels that would be incorporated into that molecule. The identity of acetyl-CoA was verified by using an acetyl-CoA standard (Sigma-Aldrich) dissolved in 1:1 ACN/water, with observation of 808.1140 and $808.1127 \mathrm{~m} / z$ unique peaks at retention times of 37.9 and 40.0 minutes, respectively. The summed intensities of these peaks and their associated isotopolog groups were then determined in liver extracts of control and HMGCS2 ASO-treated animals.

To quantify differential ${ }^{13} \mathrm{C}$-labeling of identified features, the mzXML files described above were processed in R using XCMS (84) and $\mathrm{X}^{13} \mathrm{CMS}$ (40), with the latter being modified to detect differences in ${ }^{13} \mathrm{C}$ enrichment patterns of metabolites extracted from $\left[3-{ }^{13} \mathrm{C}\right]$ pyruvate/lactate-labeled control versus HMGCS2-deficient livers (in contrast to the usual usage, in which differences are detected between unlabeled and labeled samples of the same biological type). Enrichment patterns are defined as the distribution of metabolite abundance among the various isotopolog forms of a particular metabolite. Differences in patterns were defined as changes in the shape of this distribution between biological sample types, e.g., control versus ketogenesis insufficient.

Mitochondrial isolation and respiration. Mitochondrial isolation and respiration studies were conducted and assessed as described previously $(79,85)$.

Statistics. Analyses were performed with GraphPad Prism 5.0 software (GraphPad Software). Unpaired 2-tailed Student's $t$ tests and 2-way ANOVA, with Bonferroni's correction to correct for multiple comparisons, were used as appropriate, as indicated within the text and figure legends. Data are presented as the means \pm SEM unless otherwise indicated. A $P$ value of less than 0.05 was considered significant, except for the LC/MS studies, in which a $P$ value of less than 0.01 was considered significant.

Study approval. All experiments were conducted using protocols approved by the Animal Studies Committee of Washington University.

\section{Acknowledgments}

We thank Rebecca Schugar and Christine Des Rosiers for helpful discussions; Laura Kyro for assistance with graphics; and Debra Whorms, Xia Ge, and Ashley Moll for technical 
assistance. This work was supported by grants from the NIH (DK-091538, to P.A. Crawford); the Diabetes Research Center (DK-020579); the Nutrition and Obesity Research Center (DK-056341); the Digestive Disease Research Core Center (DK-052574); Training Grant HL-007873 (to D.G. Cotter); and the Children's Discovery Institute through St. Louis Children's Hospital Foundation (to P.A. Crawford).
Address correspondence to: Peter A. Crawford, Sanford-Burnham Medical Research Institute, 6400 Sanger Rd., Orlando, Florida 32827, USA. Phone: 407.745.2135; E-mail: pcrawford@ sanfordburnham.org.

Peter A. Crawford's present address is: Sanford-Burnham Medical Research Institute, Orlando, Florida, USA.
1. Loomba R, Sanyal AJ. The global NAFLD epidemic. Nat Rev Gastroenterol Hepatol. 2013;10(11):686-690.

2. Fabbrini E, et al. Intrahepatic fat, not visceral fat, is linked with metabolic complications of obesity. Proc Natl Acad Sci U S A. 2009;106(36):15430-15435.

3. Targher G, Byrne CD. Clinical Review: Nonalcoholic fatty liver disease: a novel cardiometabolic risk factor for type 2 diabetes and its complications. JClin Endocrinol Metab. 2013;98(2):483-495.

4. Targher G, Day CP, Bonora E. Risk of cardiovascular disease in patients with nonalcoholic fatty liver disease. NEnglJMed.2010;363(14):1341-1350.

5. Yang L, Li P, Fu S, Calay ES, Hotamisligil GS. Defective hepatic autophagy in obesity promotes ER stress and causes insulin resistance. Cell Metab. 2010;11(6):467-478.

6. Masuoka HC, Chalasani N. Nonalcoholic fatty liver disease: an emerging threat to obese and diabetic individuals. Ann N Y Acad Sci. 2013;1281:106-122.

7. Lin HV, Accili D. Hormonal regulation of hepatic glucose production in health and disease. Cell Metab. 2011;14(1):9-19.

8. Samuel VT, Shulman GI. Mechanisms for insulin resistance: common threads and missing links. Cell. 2012;148(5):852-871.

9. Newgard CB. Interplay between lipids and branched-chain amino acids in development of insulin resistance. Cell Metab. 2012;15(5):606-614.

10. Farese RV Jr, Zechner R, Newgard CB, Walther TC. The problem of establishing relationships between hepatic steatosis and hepatic insulin resistance. Cell Metab. 2012;15(5):570-573.

11. Sun Z, Lazar MA. Dissociating fatty liver and diabetes. Trends Endocrinol Metab. 2013;24(1):4-12.

12. Fabbrini E, Sullivan S, Klein S. Obesity and nonalcoholic fatty liver disease: biochemical, metabolic, and clinical implications. Hepatology. 2010;51(2):679-689.

13. Serviddio G, Sastre J, Bellanti F, Vina J, Vendemiale G, Altomare E. Mitochondrial involvement in non-alcoholic steatohepatitis. Mol Aspects Med. 2008;29(1-2):22-35.

14. Wei Y, Rector RS, Thyfault JP, Ibdah JA. Nonalcoholic fatty liver disease and mitochondrial dysfunction. World J Gastroenterol. 2008;14(2):193-199.

15. Serviddio G, Bellanti F, Vendemiale G, Altomare E. Mitochondrial dysfunction in nonalcoholic steatohepatitis. Expert Rev Gastroenterol Hepatol. 2011;5(2):233-244

16. Williamson J, Scholz R, Browning E. Interactions between fatty acid oxidation and the citric acid cycle in perfused rat liver. J Biol Chem. 1969;244(17):4617-4627.

17. Cotter DG, Schugar RC, Crawford PA. Ketone body metabolism and cardiovascular disease. Am JPhysiol Heart Circ Physiol. 2013;304(8):H1060-H1076.
18. Cahill GF Jr. Fuel metabolism in starvation. Annu Rev Nutr. 2006;26:1-22.

19. McGarry JD, Foster DW. Regulation of hepatic fatty acid oxidation and ketone body production. Annu Rev Biochem. 1980;49:395-420.

20. Robinson AM, Williamson DH. Physiological roles of ketone bodies as substrates and signals in mammalian tissues. Physiol Rev. 1980;60(1):143-187.

21. Hegardt FG. Mitochondrial 3-hydroxy-3-methylglutaryl-CoA synthase: a control enzyme in ketogenesis. Biochem J. 1999;338(pt 3):569-582.

22. Orii KE, Fukao T, Song XQ, Mitchell GA, Kondo N. Liver-specific silencing of the human gene encoding succinyl-CoA: 3-ketoacid CoA transferase. Tohoku J Exp Med. 2008;215(3):227-236.

23. Williamson DH, Bates MW, Page MA, Krebs HA. Activities of enzymes involved in acetoacetate utilization in adult mammalian tissues. Biochem J. 1971;121(1):41-47.

24. Bickerton AS, et al. Adipose tissue fatty acid metabolism in insulin-resistant men. Diabetologia. 2008;51(8):1466-1474.

25. Vice E, Privette JD, Hickner RC, Barakat HA. Ketone body metabolism in lean and obese women. Metabolism. 2005;54(11):1542-1545.

26. Soeters MR, et al. Effects of insulin on ketogenesis following fasting in lean and obese men. Obesity (Silver Spring). 2009;17(7):1326-1331.

27. Bergman BC, Cornier MA, Horton TJ, Bessesen DH. Effects of fasting on insulin action and glucose kinetics in lean and obese men and women. Am J Physiol Endocrinol Metab. 2007;293(4):E1103-E1111.

28. Sunny NE, Parks EJ, Browning JD, Burgess SC. Excessive hepatic mitochondrial TCA cycle and gluconeogenesis in humans with nonalcoholic fatty liver disease. Cell Metab. 2011;14(6):804-810.

29. Satapati S, et al. Elevated TCA cycle function in the pathology of diet induced hepatic insulin resistance and fatty liver. J Lipid Res. 2012;53(6):1080-1092.

30. Thumelin S, Kohl C, Girard J, Pegorier JP. Atypical expression of mitochondrial 3-hydroxy-3-methylglutaryl-CoA synthase in subcutaneous adipose tissue of male rats. J Lipid Res. 1999;40(6):1071-1077.

31. Wentz AE, et al. Adaptation of myocardial substrate metabolism to a ketogenic nutrient environment. J Biol Chem. 2010;285(32):24447-24456.

32. Cotter DG, d'Avignon DA, Wentz AE, Weber ML, Crawford PA. Obligate role for ketone body oxidation in neonatal metabolic homeostasis. J Biol Chem. 2011;286(9):6902-6910.

33. Cotter DG, Ercal B, d'Avignon DA, Dietzen DJ, Crawford PA. Impact of peripheral ketolytic deficiency on hepatic ketogenesis and gluconeogenesis during the transition to birth. J Biol Chem. 2013;288(27):19739-19749.
34. Cotter DG, Schugar RC, Wentz AE, d'Avignon DA, Crawford PA. Successful adaptation to ketosis by mice with tissue-specific deficiency of ketone body oxidation. Am JPhysiol Endocrinol Metab. 2013;304(4):E363-E374.

35. Erfle JD, Sauer F. The inhibitory effects of acylcoenzyme A esters on the pyruvate and alpha-oxoglutarate dehydrogenase complexes. Biochim Biophys Acta. 1969;178(3):441-452.

36. Tautenhahn R, Cho K, Uritboonthai W, Zhu Z, Patti GJ, Siuzdak G. An accelerated workflow for untargeted metabolomics using the METLIN database. Nat Biotechnol. 2012;30(9):826-828.

37. Ivanisevic J, et al. Toward 'omic scale metabolite profiling: a dual separation-mass spectrometry approach for coverage of lipid and central carbon metabolism. Anal Chem. 2013;85(14):6876-6884.

38. Kanehisa M, Goto S, Sato Y, Kawashima M, Furumichi M, Tanabe M. Data, information, knowledge and principle: back to metabolism in KEGG. Nucleic acids research. 2014; 42(Database issue):D199-D205.

39. Kanehisa M, Goto S. KEGG: kyoto encyclopedia of genes and genomes. Nucleic Acids Res. 2000;28(1):27-30.

40. Huang X, Chen YJ, Cho K, Nikolskiy I, Crawford PA, Patti GJ. X13CMS: global tracking of isotopic labels in untargeted metabolomics. Anal Chem. 2014;86(3):1632-1639.

41. Jones JG, Hansen J, Sherry AD, Malloy CR, Victor RG. Determination of acetyl-CoA enrichment in rat heart and skeletal muscle by $1 \mathrm{H}$ nuclear magnetic resonance analysis of glutamate in tissue extracts. Anal Biochem. 1997;249(2):201-206.

42. Williamson JR, Browning ET, Scholz R. Control mechanisms of gluconeogenesis and ketogenesis. I. Effects of oleate on gluconeogenesis in perfused rat liver.J Biol Chem. 1969;244(17):4607-4616.

43. Williamson JR, Rostand SG, Peterson MJ. Control factors affecting gluconeogenesis in perfused rat liver. Effects of 4-pentenoic acid. J Biol Chem. 1970;245(12):3242-3251.

44. Jitrapakdee S, Wallace JC. Structure, function and regulation of pyruvate carboxylase. Biochem J. 1999;340(pt 1):1-16.

45. Choudhary C, Weinert BT, Nishida Y, Verdin E, Mann M. The growing landscape of lysine acetylation links metabolism and cell signalling. Nat Rev Mol Cell Biol. 2014;15(8):536-550.

46. Choudhary C, et al. Lysine acetylation targets protein complexes and co-regulates major cellular functions. Science. 2009;325(5942):834-840.

47. Eisenberg T, et al. Nucleocytosolic depletion of the energy metabolite acetyl-coenzyme a stimulates autophagy and prolongs lifespan. Cell Metab. 2014;19(3):431-444.

48. Marino G, et al. Regulation of autophagy by cytosolic acetyl-coenzyme A. Mol Cell. 
2014;53(5):710-725.

49. Sutendra G, et al. A nuclear pyruvate dehydrogenase complex is important for the generation of acetyl-CoA and histone acetylation. Cell. 2014;158(1):84-97.

50. Wellen KE, Hatzivassiliou G, Sachdeva UM, Bui TV, Cross JR, Thompson CB. ATP-citrate lyase links cellular metabolism to histone acetylation. Science. 2009;324(5930):1076-1080.

51. Rogers LK, Valentine CJ, Szczpyka M, Smith CV. Effects of hepatotoxic doses of acetaminophen and furosemide on tissue concentrations of CoASH and CoASSG in vivo. Chem Res Toxicol. 2000;13(9):873-882.

52. Andringa KK, Bajt ML, Jaeschke H, Bailey SM. Mitochondrial protein thiol modifications in acetaminophen hepatotoxicity: effect on HMGCoA synthase. Toxicol Lett. 2008;177(3):188-197.

53. Thurston JH, Hauhart RE. Amelioration of adverse effects of valproic acid on ketogenesis and liver coenzyme A metabolism by cotreatment with pantothenate and carnitine in developing mice: possible clinical significance. Pediatr Res. 1992;31(4 pt 1):419-423.

54. Thurston JH, Hauhart RE. Reversal of the adverse chronic effects of the unsaturated derivative of valproic acid-2-n-propyl-4-pentenoic acid - on ketogenesis and liver coenzyme A metabolism by a single injection of pantothenate, carnitine, and acetylcysteine in developing mice. Pediatr Res. 1993;33(1):72-76.

55. Tokutake Y, et al. Effect of diet composition on coenzyme $A$ and its thioester pools in various rat tissues. Biochem Biophys Res Commun. 2012;423(4):781-784.

56. Li LO, Hu YF, Wang L, Mitchell M, Berger A, Coleman RA. Early hepatic insulin resistance in mice: a metabolomics analysis. Mol Endocrinol. 2010;24(3):657-666.

57. Garcia M, Leonardi R, Zhang YM, Rehg JE, Jackowski S. Germline deletion of pantothenate kinases 1 and 2 reveals the key roles for CoA in postnatal metabolism. PLoS One. 2012;7(7):e40871.

58. Leonardi R, Rehg JE, Rock CO, Jackowski S. Pantothenate kinase 1 is required to support the metabolic transition from the fed to the fasted state. PLoS One. 2010;5(6):e11107.

59. Mitchell GA, Gauthier N, Lesimple A, Wang SP, Mamer O, Qureshi I. Hereditary and acquired diseases of acyl-coenzyme A metabolism. Mol Genet Metab. 2008;94(1):4-15.

60. Meertens LM, Miyata KS, Cechetto JD, Rachubinski RA, Capone JP. A mitochondrial ketogenic enzyme regulates its gene expression by associ- ation with the nuclear hormone receptor PPAR $\alpha$. ЕМВО J.1998;17(23):6972-6978.

61. Kostiuk MA, Keller BO, Berthiaume LG. Palmitoylation of ketogenic enzyme HMGCS2 enhances its interaction with PPAR $\alpha$ and transcription at the Hmgcs2 PPRE. FASEB J. 2010;24(6):1914-1924.

62. Vila-Brau A, De Sousa-Coelho AL, Mayordomo C, Haro D, Marrero PF. Human HMGCS2 regulates mitochondrial fatty acid oxidation and FGF21 expression in HepG2 cell line. J Biol Chem. 2011;286(23):20423-20430.

63. Chakravarthy MV, et al. Identification of a physiologically relevant endogenous ligand for PPARo in liver. Cell. 2009;138(3):476-488.

64. Cohen JC, Horton JD, Hobbs HH. Human fatty liver disease: old questions and new insights. Science. 2011;332(6037):1519-1523.

65. Anstee QM, Targher G, Day CP. Progression of NAFLD to diabetes mellitus, cardiovascular disease or cirrhosis. Nat Rev Gastroenterol Hepatol. 2013;10(6):330-344.

66. Ramos M, et al. New case of mitochondrial HMG-CoA synthase deficiency. Functional analysis of eight mutations. Eur JMed Genet. 2013;56(8):411-415.

67. Wolf NI, Rahman S, Clayton PT, Zschocke J. Mitochondrial HMG-CoA synthase deficiency: identification of two further patients carrying two novel mutations. Eur J Pediatr. 2003;162(4):279-80.

68. Bouchard L, et al. Mitochondrial 3-hydroxy-3-methylglutaryl-CoA synthase deficiency: clinical course and description of causal mutations in two patients. Pediatr Res. 2001;49(3):326-331.

69. Aledo R, et al. Genetic basis of mitochondrial HMG-CoA synthase deficiency. Hum Genet. 2001;109(1):19-23.

70. Morris AA, Lascelles CV, Olpin SE, Lake BD, Leonard JV, Quant PA. Hepatic mitochondrial 3-hydroxy-3-methylglutaryl-coenzyme a synthase deficiency. Pediatr Res. 1998;44(3):392-396.

71. Thompson GN, Hsu BY, Pitt JJ, Treacy E, Stanley CA. Fasting hypoketotic coma in a child with deficiency of mitochondrial 3-hydroxy-3-methylglutaryl-CoA synthase. $N$ EnglJ Med. 1997;337(17):1203-1207.

72. Ratziu V. Pharmacological agents for NASH. Nat Rev Gastroenterol Hepatol. 2013;10(11):676-685.

73. Mahendran Y, et al. Association of ketone body levels with hyperglycemia and type 2 diabetes in 9,398 finnish men. Diabetes. 2013;62(10):3618-3626.

74. Shimazu T, et al. SIRT3 deacetylates mitochondrial 3-hydroxy-3-methylglutaryl CoA synthase 2 and regulates ketone body production. Cell Metab. 2010;12(6):654-661.
75. Sengupta S, Peterson T, Laplante M, Oh S, Sabatini D. mTORC1 controls fasting-induced ketogenesis and its modulation by ageing. Nature. 2010;468(7327)(7327)

76. Grimsrud PA, et al. A quantitative map of the liver mitochondrial phosphoproteome reveals posttranslational control of ketogenesis. Cell Metab. 2012;16(5):672-683.

77. Quant PA, Tubbs PK, Brand MD. Glucagon activates mitochondrial 3-hydroxy-3-methylglutarylCoA synthase in vivo by decreasing the extent of succinylation of the enzyme. Eur J Biochem. 1990;187(1):169-174.

78. Rardin MJ, et al. SIRT5 Regulates the Mitochondrial Lysine Succinylome and Metabolic Networks. Cell Metab. 2013;18(6):920-933.

79. Crawford PA, et al. Regulation of myocardial ketone body metabolism by the gut microbiota during nutrient deprivation. Proc Natl Acad Sci U S A. 2009;106(27):11276-11281.

80. Cotter DG, Ercal B, Andre d'Avignon D, Dietzen DJ, Crawford PA. Impairments of hepatic gluconeogenesis and ketogenesis in PPARalpha-deficient neonatal mice. Am J Physiol Endocrinol Metab. 2014;307(2):E176-E185.

81. Chambers MC, et al. A cross-platform toolkit for mass spectrometry and proteomics. Nat Biotechnol. 2012;30(10):918-920.

82. Tautenhahn R, Patti GJ, Rinehart D, Siuzdak G. XCMS Online: a web-based platform to process untargeted metabolomic data. Anal Chem. 2012;84(11):5035-5039.

83. Chen YJ, et al. Inflammation triggers production of dimethylsphingosine from oligodendrocytes. Neuroscience. 2014;279C:113-121.

84. Smith CA, Want EJ, O'Maille G, Abagyan R, Siuzdak G. XCMS: processing mass spectrometry data for metabolite profiling using nonlinear peak alignment, matching, and identification. Anal Chem. 2006;78(3):779-787.

85. Schugar RC, Huang X, Moll AR, Brunt EM, Crawford PA. Role of choline deficiency in the Fatty liver phenotype of mice fed a low protein, very low carbohydrate ketogenic diet. PLoS One. 2013;8(8):e74806.

86. Merritt ME, Harrison C, Sherry AD, Malloy $\mathrm{CR}$, Burgess SC. Flux through hepatic pyruvate carboxylase and phosphoenolpyruvate carboxykinase detected by hyperpolarized $13 \mathrm{C}$ magnetic resonance. Proc Natl Acad Sci U S A. 2011;108(47):19084-19089.

87. Befroy DE, et al. Direct assessment of hepatic mitochondrial oxidative and anaplerotic fluxes in humans using dynamic $13 \mathrm{C}$ magnetic resonance spectroscopy. Nat Med.2014;20(1):98-102. 